\title{
Sensitivity Analysis of the Army Training and Testing Area Carrying Capacity (ATTACC) Model to User- specified Starting Parameters
}

Alan B. Anderson

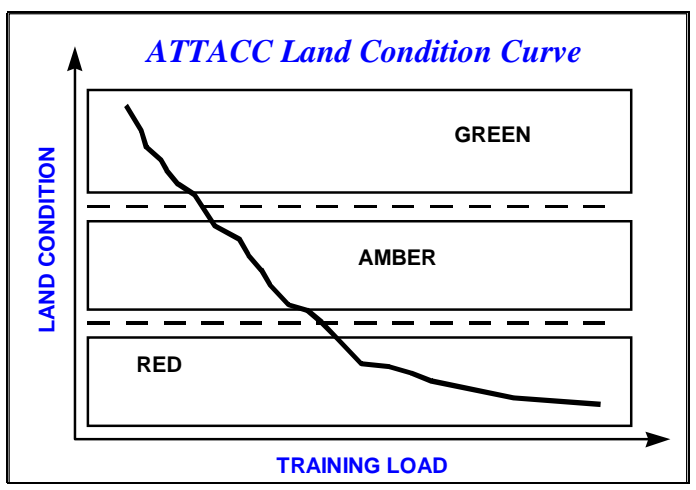

Sensitivity analysis is useful in formulation, calibration, and verification of environmental models. Sensitivity analysis of a model's responses to variations in input values can be used to indicate the relative importance of individual input values. Emphasis can then be placed on developing and refining those data that have the greatest influence on the model output.

The Army Training and Testing Area Carrying Capacity (ATTACC) program is a methodology for estimating training and testing land carrying capacity. The methodology is used to determine land rehabilitation and maintenance costs associated with land-based training and other uses. ATTACC is part of the Army's Integrated Training Area Management (ITAM) Program.

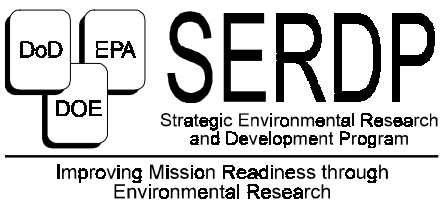




\section{Foreword}

This study was conducted for the Strategic Environmental Research and Development Program (SERDP) Office under Funding Authorization Document (FAD) 0400-98-8141-08, Work Unit EL8 "Improved Units of Measure for Training and Testing Area Carrying Capacity." The technical monitor was Dr. Robert Holst, Conservation Program Manager. Mr. Bradley P. Smith is the Executive Director, SERDP.

Baseline data used in this study were initially developed for the U.S. Army Envi-

ronmental Center (AEC) as a part of an ATTACC Implementation Project under Military Interdepartmental Purchase Request (MIPR) No. 5947; Work Unit P07, "Army Training and Testing Area Carrying Capacity." The technical monitor was Mr. Steve Sekscieski, SFIM-AEC-EQN.

The work was performed by the Ecological Processes Branch (CN-N) of the Installations Division (CN), Construction Engineering Research Laboratory (CERL). The CERL Principal Investigator was Alan B. Anderson. Dr. Harold E. Balbach is Chief, CECER-CN-N, and Dr. John T. Bandy is Division Chief, CECER-CN. The technical editor was Gloria J. Wienke, Information Technology Laboratory.

Thanks to the Integrated Training Area Management personnel at Fort Hood, Texas, and the Combat Maneuver Training Center (CMTC), Hohenfels, Germany, for allowing use of installation data.

The Director of CERL is Dr. Michael J. O'Connor. 


\section{Contents}

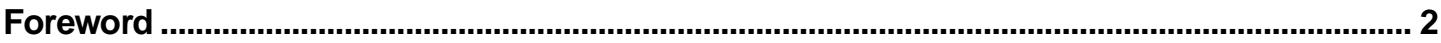

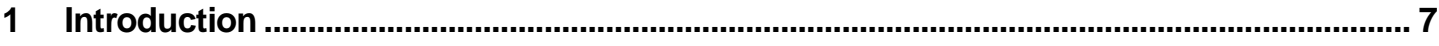

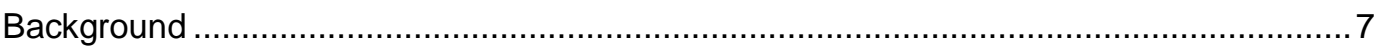

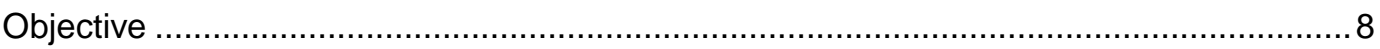

Approach

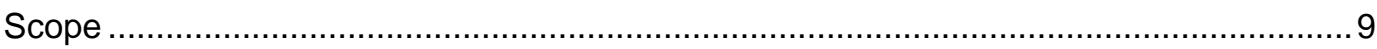

Mode of Technology Transfer.............................................................................

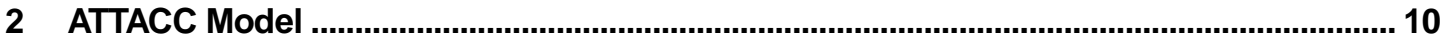

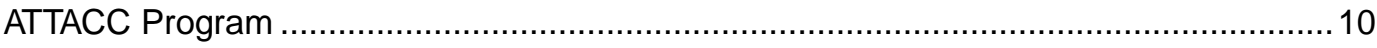

ATTACC Main Model Description ..........................................................................

ATTACC Training Load Component Description..........................................................11

ATTACC Training Load Data Descriptions and Data Sources .........................................12

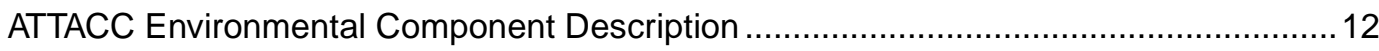

ATTACC Environmental Input Data Descriptions and Data Sources .................................14

ATTACC Cost Analysis Component Description ...........................................................17

ATTACC Cost Analysis Input Data Descriptions and Data Sources ................................18

3 ATTACC Main Model Sensitivity Analysis .................................................................... 19

Fixed Input Variation Effects on Model Output ........................................................ 19

Analysis of Variance of Fixed Input Effects on Model Output ......................................21

Average Linear Sensitivity Coefficient for ATTACC Main Model Input Variables...............22

4 ATTACC Training Characterization Component Sensitivity Analysis................................. 25

Fixed Input Variation Effects on Model Output ..........................................................25

Analysis of Variance of Fixed Input Effects on Model Output .......................................27

Average Linear Sensitivity Coefficient for ATTACC Training Load Component Input

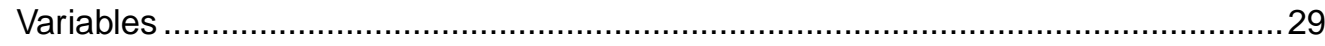

5 ATTACC Environmental Component Sensitivity Analysis .................................................30

Fixed Input Variation Effects on Model Output ............................................................ 30

Analysis of Variance of Fixed Input Effects on Model Output ...........................................34

Average Linear Sensitivity Coefficient for ATTACC Environmental Component Input Variables. 


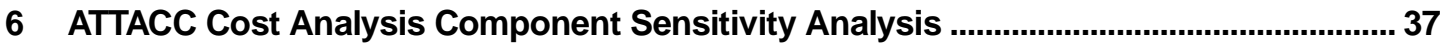

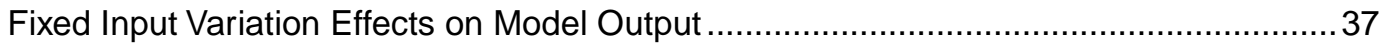

Analysis of Variance of Fixed Input Effects on Model Output ........................................39

Average Linear Sensitivity Coefficient for ATTACC Cost Analysis Component Input

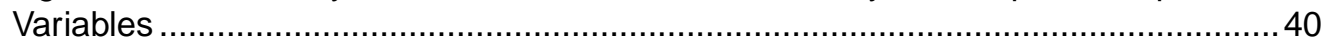

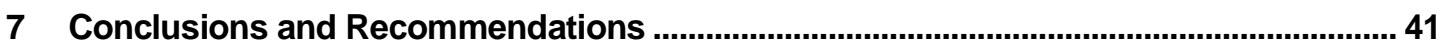

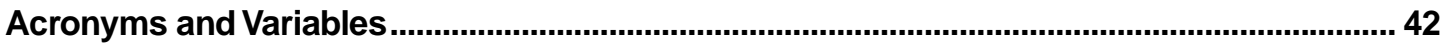

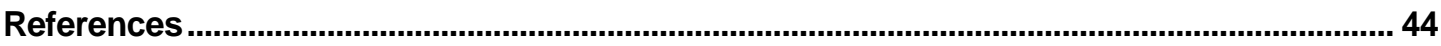

Distribution 


\section{List of Figures and Tables}

\section{Figures}

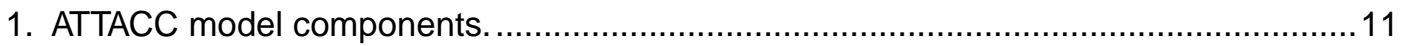

2. ATTACC Environmental component land condition curve. ......................................... 14

3. Effect of changes in total cost values on ATTACC model outputs. ................................20

4. Effect of changes in training load values on ATTACC model outputs............................20

5. Effect of changes in land condition values on ATTACC model outputs. .........................21

6. Effect of changes in management goals on ATTACC model outputs. ............................21

7. Single degree of freedom sum of squares plotted against the chi-square

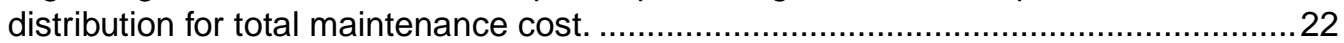

8. Effect of changes in annual mileage estimates on training load factor estimates

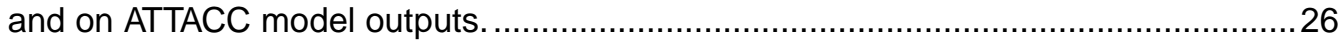

9. Effect of changes in vehicle severity factors values on training load factor estimates and on ATTACC model outputs.

10. Effect of changes in event severity factor values on training load factor estimates and on ATTACC model outputs.

11. Effect of changes in vehicle off-road factor values on training load factor estimates and on ATTACC model outputs.

12. Effect of changes in vehicle conversion factor values on training load factor estimates and on ATTACC model outputs.

13. Single degree of freedom sum of squares plotted against the chi-square distribution for training load, average erosion status, percent lands with ES greater than 1, and percent lands with ES greater than 2 .

14. Effect of changes in $C$ factor input values on ATTACC model outputs.

15. Effect of changes in impact factor input values on ATTACC model outputs. .................31

16. Effect of changes in $\mathrm{K}$ factor input values on ATTACC model outputs. ........................... 31

17. Effect of changes in LS factor input values on ATTACC model outputs. .......................32

18. Effect of changes in T factor input values on ATTACC model outputs.......................... 32

19. Effect of changes in $R$ factor input values on ATTACC model outputs. .........................32

20. Effect of changes in $P$ factor input values on ATTACC model outputs. ......................... 32

21. Effect of changes in recovery factor input values on ATTACC model outputs...............33

22. Effect of changes in training load factor input values on ATTACC model outputs........33

23. Effect of changes in maximum $C$ factor parameter values on ATTACC model outputs. 
24. Effect of changes in shape of recovery factor curve on ATTACC model outputs. ........33

25. Effect of changes in shape of impact factor curve on ATTACC model outputs.............34

26. Effect of changes in net maneuver area on ATTACC model outputs............................34

27. Single degree of freedom sum of squares plotted against the chi-square distribution for average erosion status, percent lands with ES greater than 1, and percent lands with ES greater than 2 .

28. Effect of changes in repair practice area affected values on ATTACC model

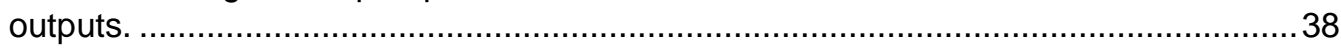

29. Effect of changes in land repair effectiveness values on ATTACC model outputs........38

30. Effect of changes in variable costs values on ATTACC model outputs..........................38

31. Effect of changes in fixed cost values on ATTACC model outputs. ............................... 38

32. Single degree of freedom sum of squares plotted against the chi-square distribution for total maintenance cost.

\section{Tables}

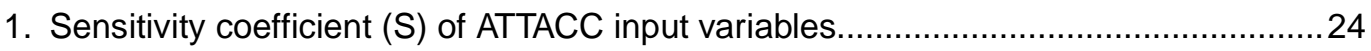

2. Sensitivity $(S)$ coefficient values for training characterization component input

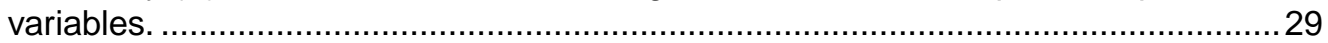

3. Sensitivity coefficient (S) values for environmental component input variables...........36

4. Sensitivity coefficient (S) values for training characterization component input variables. 


\section{Introduction}

\section{Background}

The Department of Defense (DoD) is responsible for administering more than 25 million acres of Federally-owned land in the United States (Public Land Law Review Commission 1970), making it the fifth largest Federal land-managing agency. In addition, DoD military branches have agreements with states and other Federal land-managing agencies to allow training use of 15 million acres (Council of Environmental Quality 1989).

The Integrated Training Area Management (ITAM) Program is the Army's program for managing training land. A major objective of ITAM has been to develop a method for estimating training land carrying capacity. Training land carrying capacity is defined by the Office of the Deputy Chief of Staff for Operations and Plans (ODCSOPS) as the amount of training that a given parcel of land can accommodate in a sustainable manner, based on a balance of use, condition, and maintenance practices. The Army Training and Testing Area Carrying Capacity (ATTACC) program is an initiative sponsored by the ODCSOPS and the Assistant Secretary of the Army for Installations, Logistics, and Environment [ASA (IL\&E)] to estimate training land carrying capacity. ODCSOPS is the proponent for the ATTACC program.

The ATTACC methodology is used to estimate training and testing land carrying capacity and to determine land rehabilitation and maintenance costs associated with land-based training and other uses. The ATTACC Handbook (U.S. Army Environmental Center 1999) documents the standard operating procedures for implementing ATTACC.

Development of any model, including ATTACC, requires two general steps: (1) development of the model equations from existing theory and basic principles; and (2) evaluation of the model. The evaluation process includes at least three steps: (1) sensitivity analysis of the model responses to input parameters; (2) validation of the model by comparison of results to measured data; and (3) evaluation of confidence limits for the model predictions. Sensitivity analysis is an evaluation of the magnitude of changes in the model response as a function of changes in the values of model input parameters. A sensitivity analysis of a 
model's responses to variations in input values can be used to indicate the relative importance of individual input values. Emphasis can then be placed on developing and refining those data that have the greatest influence on the model output. Validation of the model using measured data and evaluation of the confidence limits for the model predictions indicate the reliability of the model.

The ATTACC model was developed using currently available models and knowledge about training practices, environmental conditions, and land maintenance practices. Although studies to validate components and quantify confidence limits are ongoing, the sensitivity analysis of the ATTACC model has been completed by the U.S. Army Construction Engineering Research Laboratory (CERL) and is documented in this report.

The analyses contained in this report are intended to assist ITAM personnel and others responsible for implementing ATTACC and to help establish policy related to the ATTACC methodology. The sensitivity analysis provides useful information for formulating, calibrating, and verifying the ATTACC methodology. Results provide a basis upon which to prioritize future model development and refinement. Results also provide a basis to evaluate the effect of alternative data sources on ATTACC model predictions.

\section{Objective}

The objective of this study is to perform an objective, detailed sensitivity analysis of the ATTACC model to assess overall influence of input parameter values on predicted land maintenance costs. Sensitivity analysis was conducted on training load, environmental, and cost analysis components of the model. The main input parameters for each component were evaluated.

\section{Approach}

Two installations were selected for conducting a sensitivity analysis of the ATTACC model. The installations were selected based on availability of data and leveraged research efforts related to the ATTACC program. The ATTACC model was parameterized (parameters were defined) using data from these installations.

First, fixed percentage variations in individual input values were used to quantify the effect of changes to each input variable on model predictions. This analysis was intended to identify the variables that most affected model predic- 
tions. The analysis also indicates which input variables are linearly related to the ATTACC model outputs. Graphs are provided to illustrate the effect of changes in input values on model predictions.

A series of simulation runs were arranged in a designed experiment. Analysis of variance (ANOVA) was used to identify significant starting conditions based on attributes of the installation natural resources. The ANOVA was also used to identify significant interactions between input variables on model predictions. Probability plots of the sum of squares associated with the model parameters were used to visually rank the relative importance of input variables on model outputs.

An average linear sensitivity coefficient $(\mathrm{S})$ for the change in model response relative to the values of input parameters was estimated for each input variable. The $\mathrm{S}$ coefficient represents a relative normalized change in output to a normalized change in input, which allows a means of comparing sensitivities for input parameters that have different orders of magnitude.

\section{Scope}

This report analyzes the ATTACC model as described in the ATTACC Handbook (U.S. Army Environmental Center 1999). The sensitivity analysis includes the environmental, training load, and cost analysis components of the ATTACC methodology. Multiple year and regional extrapolation methodology extensions are not specifically included in this report, though the results are applicable to these extensions of the ATTACC model.

\section{Mode of Technology Transfer}

The information in this report will be provided to Army personnel responsible for ATTACC implementation. The information will also be provided to organizations responsible for developing and refining the ATTACC methodology. 


\section{The ATTACC Model}

\section{ATTACC Program}

The ITAM Program is the Army's strategy for managing training land. A major objective of ITAM has been to develop a method for estimating training land carrying capacity. Training land carrying capacity is defined by ODCSOPS as the amount of training that a given parcel of land can accommodate in a sustainable manner, based on a balance of use, condition, and maintenance practices. Development of the ATTACC methodology is an initiative sponsored by ODCSOPS and ASA (IL\&E). ATTACC is part of ITAM. The ODCSOPS is the ATTACC proponent.

ATTACC is a methodology for estimating training and testing land carrying capacity. The methodology is also used to determine land rehabilitation and maintenance costs associated with land-based training and other uses. The ATTACC Handbook (U.S. Army Environmental Center 1999) provides the standard operating procedures for implementing ATTACC at ITAM installations.

\section{ATTACC Main Model Description}

The ATTACC model consists of three components: training load, environmental, and cost analysis (Figure 1). The training load component characterizes training load in terms of Maneuver Impact Miles (MIM). One MIM is the equivalent impact of an M1A2 tank traveling 1 mile while participating in an armor battalion field training exercise (FTX). The environmental component characterizes land condition in terms of erosion status. Erosion status (ES) is the ratio of predicted erosion rates to tolerable erosion rates. Erosion rates are estimated using a modification of the Revised Universal Soil Loss Equation (RUSLE). The cost analysis component of ATTACC characterizes installation land maintenance and repair practices in terms of the type of practice, costs, area affected, and associated effectiveness. Cost factors are calculated and expressed in dollars per mile for each vehicle type. Total installation maintenance funding requirements are also estimated. 


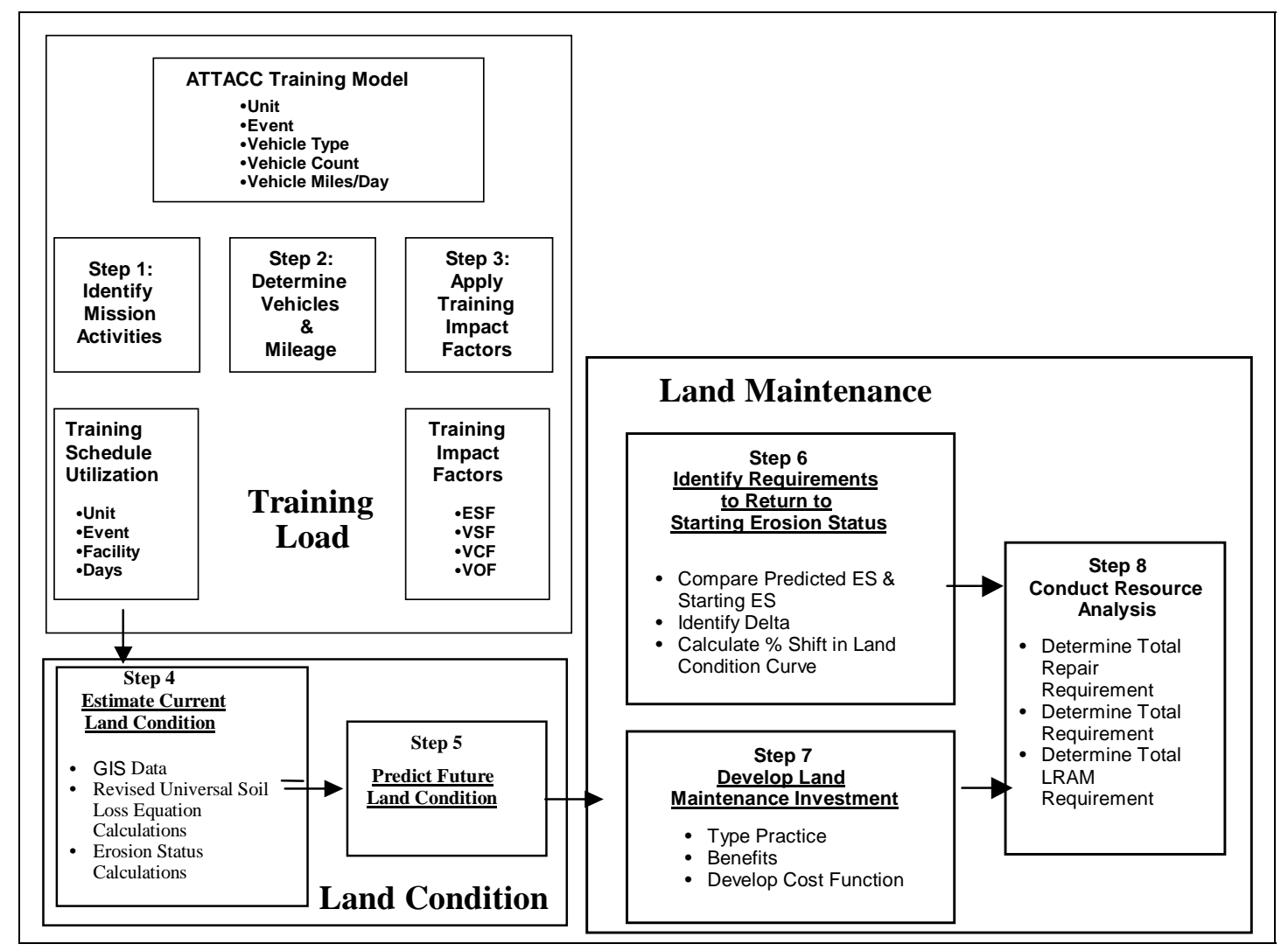

Figure 1. ATTACC model components.

\section{ATTACC Training Load Component Description}

Training load is the term used to describe the collective impact of all military activities that occur on a given parcel of land. ATTACC measures training load in terms of MIM. The MIM value for each mission activity is derived from the number and types of vehicles used, the miles that the vehicles travel, and the type of training event.

The mathematical equation for calculating an installation's training load in ATTACC is shown in Equation 1. Training load is calculated using Training Impact Factors (TIFs). The TIFs are the Event Severity Factor (ESF), Vehicle Severity Factor (VSF), Vehicle Off-road Factor (VOF), and Vehicle Conversion Factor (VCF). The ESF is a multiplier that represents the relative impact of an event, as compared to the standard event (Armor Battalion FTX). The VSF is a multiplier that represents the relative impact of a vehicle, as compared to the standard vehicle (M1A2 tank). The VOF is a multiplier that represents the percentage of vehicle mileage typically driven off improved roads. The VCF is a multiplier that represents the area impacted by a vehicle, as compared to the area impacted by the standard vehicle. 
MIMs $=\sum_{E=1}^{e}\left[\left(\sum_{V=1}^{v}\left(\right.\right.\right.$ Number $_{V} *$ Mileage $\left.\left._{V} * V S F_{V} * V O F_{V} * V C F_{V}\right)\right) *$ Duration $_{E} *$ ESF $\left._{E}\right]$

[Eq 1]

where:

MIM = normalized training load (maneuver impact miles)

$\mathrm{E} \quad=$ event (dimensionless)

e $\quad=$ number of events (dimensionless)

$\mathrm{V} \quad=$ vehicle type (dimensionless)

$\mathrm{v}=$ number of types of vehicles in event $\mathrm{E}$ (dimensionless)

Mileage = daily mileage for vehicle type $\mathrm{V}$ for event type $\mathrm{E}$ (miles)

Number = number of vehicles of type $\mathrm{V}$ (dimensionless)

VSF = vehicle severity factor for vehicle type $\mathrm{V}$ (dimensionless)

VOF = vehicle off-road factor for vehicle type $\mathrm{V}$ (dimensionless)

$\mathrm{VCF} \quad=$ vehicle conversion factor for vehicle type $\mathrm{V}$ (dimensionless)

Duration = number of days for event type $\mathrm{V}$ (days)

$\mathrm{ESF} \quad=$ event severity factor for event type $\mathrm{V}$ (dimensionless)

\section{ATTACC Training Load Data Descriptions and Data Sources}

Training load projections are based on Army training doctrine, and databases (Battalion Level Training Model [BLTM] and Combined Arms Training Strategy [CATS]). These sources identify the number, type, and duration of events that various unit types will conduct annually. This information, when combined with unit stationing information from the Army Stationing and Installation Plan (ASIP), provides an estimate of a projected training load. Alternatively, training load information can be obtained from the Range Facility Management Support System (RFMSS) software program. These data sources provide the type of event, number and type of vehicles, and mileage projections.

The ESF, VSF, and VOF values are currently derived using expert opinion. The VCF values are based on published vehicle tire/track widths.

\section{ATTACC Environmental Component Description}

The ATTACC methodology estimates land condition in terms of the average erosion status. ES is the ratio of predicted erosion rates to tolerable erosion rates. Erosion status is estimated using a modification of RUSLE. 
The ATTACC environmental component modeling is done within a geographic information system (GIS) using a raster data model. A raster data model represents the map area as an array of equal sampling units (grid cells). The spatial location of features in a raster data model is implicit from their position in the array.

Current land condition in the ATTACC model, as estimated by erosion status, is calculated for each grid cell. A map calculation using the RUSLE and ES equations is used to estimate current land condition (Equations 2 and 3). Once the current land condition is calculated for each grid cell, an average land condition can be calculated by averaging the erosion status values for each cell within a given area.

where:

$\mathrm{A}=$ soil loss per unit area (tons $\mathrm{ac}^{-1} \mathrm{yr}^{-1}$ )

$\mathrm{R}$ = rainfall and runoff factor ([hundreds of ft-tons] inch $\mathrm{ac}^{-1} \mathrm{hr}^{-1} \mathrm{yr}^{-1}$ )

$\mathrm{K}=$ soil erodibility factor (tons hr [hundreds of ft-tons] ${ }^{-1} \mathrm{in}^{-1}$ )

LS = slope length and steepness factor (dimensionless)

$\mathrm{C}$ = cover and management factor (dimensionless)

$\mathrm{P} \quad$ = support practice factor (dimensionless).

$\mathrm{ES}=\mathrm{A} / \mathrm{T}$

[Eq 3]

where:

$\mathrm{ES}=$ Erosion Status (dimensionless)

$\mathrm{A}=$ soil loss per unit area (tons $\mathrm{ac}^{-1} \mathrm{yr}^{-1}$ )

$\mathrm{T}=$ soil loss tolerance factor (tons $\mathrm{ac}^{-1} \mathrm{yr}^{-1}$ ).

Military training damages soils and vegetation. Therefore, soils are more exposed to raindrop impact and surface water runoff, resulting in an overall degradation of land condition. The more the land is impacted, the more the vegetative cover loss and the greater the degradation of land condition. This relationship is conceptually modeled as shown in Equation 4.

$$
L C_{P}=L C_{C}+\Delta L C_{T}-\Delta L C_{R}
$$

where: 
$\mathrm{LC}_{\mathrm{P}} \quad=$ predicted land condition

$\mathrm{LC}_{\mathrm{C}} \quad=$ current land condition

$\Delta \mathrm{LC}_{\mathrm{T}}=$ change is land condition due to training

$\Delta \mathrm{LC}_{\mathrm{R}}=$ change in land condition due to natural recovery

Performing all mathematical operations within a GIS on a cell-by-cell basis solves the equation. Future land condition is calculated as the average annual predicted ES value for the land area of interest. Equation 4 includes the current land condition, change in land condition due to training, and change in land condition due to natural recovery. To create a curve representing the relationship between land condition and training load, the predicted erosion status calculation is estimated for a range of MIM values. Figure 2 shows a hypothetical land condition curve. As training load increases, land condition becomes worse.

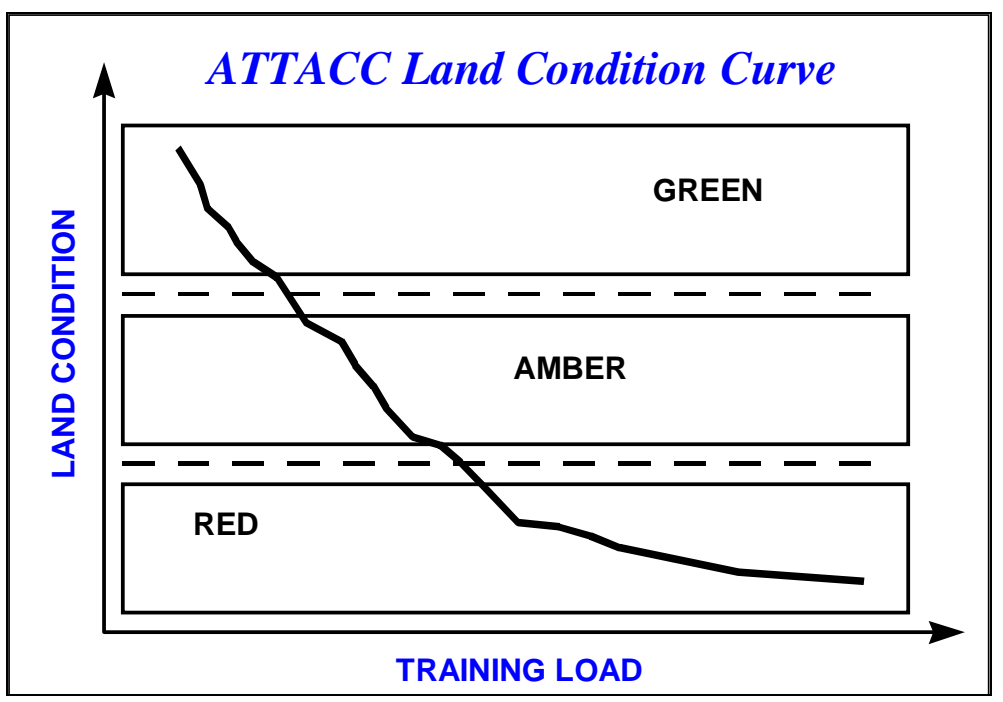

Figure 2. ATTACC Environmental component land condition curve.

\section{ATTACC Environmental Input Data Descriptions and Data Sources}

The RUSLE $R$ factor is the rainfall and runoff factor or erosivity factor for a specific location. The $\mathrm{R}$ factor is a quantitative expression of the erosivity of local average annual precipitation and runoff. The $\mathrm{R}$ factor incorporates the amount, intensity, and duration patterns of precipitation. $R$ factor values for the United States can be obtained from published isoerodent maps from a variety of sources (Renard et al 1997). $\mathrm{R}$ factor values for the United States are also available by county from the RUSLE computer program CITY database (Renard et al. 1997). Published $\mathrm{R}$ factor values are also available for other countries (Rogler and 
Schwertmann 1981). $R$ factor values can also be calculated directly from local precipitation data (Renard et al. 1997). Published isoerodent maps are the primary source of $\mathrm{R}$ factor values for the ATTACC model.

The soil-erodibility $(\mathrm{K})$ factor is the rate of soil loss per rainfall erosion index unit under standardized conditions. K factor values can be calculated from soil samples using a soil-erodibility nomograph (Wischmeier, Johnson, and Cross 1971; Wischmeier and Smith 1978; Renard et al. 1997) and algebraic approximations of the nomograph (Renard et al 1997). When $\mathrm{K}$ factor values are estimated from soil samples, they are extrapolated across the installation using soil maps, remotely sensed imagery, plot allocation strata, or other data sources as available. $\mathrm{K}$ factor values are also available with most published soil surveys from the U.S. Department of Agriculture's (USDA) Natural Resource Conservation Service (NRCS). K values associated with NRCS soil surveys are the primary source of data for ATTACC.

The soil loss tolerance (T) factor indicates the maximum level of soil erosion that will permit a high level of soil productivity to be sustained economically and indefinitely. T values are based on soil depth, rooting depth, soil organic matter reduction, and plant nutrient losses. $\mathrm{T}$ factor values are available with most published soil surveys from the NRCS. T factor values for the ATTACC model are generally obtained from NRCS soil surveys.

The slope length and steepness (LS) factor provides a quantitative representation of both the slope length and steepness. Slope steepness and length values for the LS equations can be determined from topographic maps, digital elevation models (DEMs), average values from soil mapping units, or from direct field measurement. Existing GIS products have automated the calculation of LS factors from DEM products. The choice of the data source for determining the LS factor for ATTACC depends on the data available for each study area and the resolution and quality of the data. In the current implementation of ATTACC, LS data layers generally were developed from 30m x 30m DEMs and/or LS factors, using Land Condition Trend Analysis (LCTA) data extrapolated across the installation with soil maps.

The vegetative cover $(\mathrm{C})$ factor reflects the degree of erosion protection provided by vegetative cover. The cover factor describes the density and structure of the vegetative canopy cover and kind and amount of cover in contact with the soil. $\mathrm{C}$ factor data for the ATTACC model generally were estimated from LCTA field data and extrapolated using remote sensed imagery, vegetation maps, or sample strata. The $\mathrm{C}$ factor can be estimated from field observations and/or remotely sensed data. Nomographs have been developed to estimate $\mathrm{C}$ factor values using 
field data (Wischmeier and Smith 1978). Algebraic approximations of the nomograph have been developed and incorporated into computer programs that make use of LCTA data (Anderson et al. 1995). When C factor values are estimated from field data, they must be extrapolated across the installation. Many available extrapolation methods make use of vegetation maps, soils maps, plot allocation strata maps, remote sensing, and other GIS data layers. The choice of the data source for determining the $\mathrm{C}$ factor depends on the data available at an installation and the resolution and quality of that data. LCTA data frequently is extrapolated using remote sensing or vegetation maps.

The conservation practices $(\mathrm{P})$ factor is a quantitative expression of the mitigating effect that conservation practices have on the erosion process. Conservation practices consist of seeding, site hardening, terraces, and other practices. $\mathrm{P}$ factor values are obtained from published data or expert opinion.

The ATTACC methodology requires a map of all installation lands available for training and those areas with use restrictions. Training lands include lands available for training, under installation control, and that are the responsibility of the installation to maintain as part of the ITAM Program. Combining and reclassifying a number of thematic data layers within a GIS produces a training lands map. These data layers frequently include the installation boundary, cantonment, water, impact areas, and other data layers that capture restricted uses.

The change in ES due to mission activities is estimated by determining the change in the $\mathrm{C}$ factor value due to a single pass of an M1A2. Controlled studies, field measurements, and/or subject matter experts are used to estimate mission impacts. In the ATTACC model, LCTA data frequently is used to estimate mission impacts. Controlled field studies are used when available.

The recovery period is the amount of time required for a sufficient amount of vegetative cover to return the soil erosion rates on a disturbed site to the predisturbance rates. Recovery rate data is available from a variety of sources. Recovery rate data can be obtained from controlled studies at installations or from similar ecosystems, or from subject matter experts. Estimated recovery rates are associated with vegetation type, soil type, or another spatially distributed land features, so that the information can be extrapolated across the installation. In the ATTACC methodology, installation ITAM personnel usually provide estimates of recovery rates and recommend extrapolation methods. Expert opinions were validated using experimental data where available.

Land use activities are spatially distributed across the installation. Historic disturbance patterns are used as a surrogate measure of future training use distri- 
bution. To spatially extrapolate historic data, measures of disturbance from field plots are statistically related to one or more spatial data. LCTA plot data are often used to quantify disturbance. LCTA disturbance data is then averaged by training area (Linn and Gordon 1993), related to remotely sensed imagery (Wu and Westervelt 1994), or related to GIS spatial data (Guertin et al. 1997). In the absence of ground truth data, remotely sensed imagery is used to estimate the percentage of area that is denuded of vegetation (Sedlak and Brown 1992). In the ATTACC methodology, LCTA disturbance data was most frequently correlated with remotely sensed imagery and GIS data to estimate land use distribution patterns.

\section{ATTACC Cost Analysis Component Description}

The ATTACC land condition curve and training load estimates are used to predict future land condition. The difference between the predicted future land condition and a management goal is an indicator of the amount of land maintenance required. This difference is expressed as a percentage of the predicted land condition. This value (delta shift factor) is the percentage shift in the land condition curve required to make the predicted land condition equal the management goal. Land maintenance funding requirements are based on the size of the delta shift factor, the types of land maintenance activities commonly used at an installation, the cost of these activities, the effectiveness of these activities, and the area affected by these activities.

Total costs include variable and fixed costs. Variable costs include activities that directly affect land condition, and whose use will shift the land condition curve. Fixed costs include activities that do not directly affect the land condition curve, but whose expense is part of the cost of maintaining an installation. Seeding is an example of a variable cost practice. Equipment purchases are an example of fixed costs.

ATTACC quantifies the benefits of variable land maintenance practices based on the mitigating effect they have on erosion. The effectiveness ( $\mathrm{P}$ factor) associated with each activity has a value between from 0 to 1 , where lower values represent more effective practices.

To develop a cost function, ATTACC combines the cost of the practices with their ability to mitigate erosion. The number, type, and cost of land maintenance practices are identified from historical records. Practices are divided into fixed and variable cost activities. The number of acres affected by each variable cost practice and its effectiveness is estimated. The total cost of variable cost practices is 
divided by the weighted average effectiveness. This results in a cost estimate for a 1 percent change in the land condition curve. The total variable cost requirement is calculated by multiplying the delta shift factor by the 1 percent change in land condition cost. The total variable cost requirement is the cost to change the predicted erosion status from the predicted land condition to the land condition goal. Fixed costs are the average historical cost of fixed cost activities. Total land maintenance costs are the sum of the fixed and variable cost estimates. The equation for estimating total installation land maintenance and repair costs is shown in Equation 5.

$c_{t}=\left(\frac{l_{p}-l_{g}}{l_{p}}\right)\left(\frac{\left(\sum_{v=1}^{n} c_{v}\right)}{\left(\left(\sum_{v=1}^{n} a_{v} p_{v}\right) /\left(\sum_{v=1}^{n} a_{v}\right)\right)}\right)+\sum_{f=1}^{n} c_{f}$

where

$\mathrm{c}_{\mathrm{t}}=$ total cost (dollars)

$\mathrm{c}_{\mathrm{v}}=$ cost of variable activity $\mathrm{v}$ (dollars)

$\mathrm{c}_{\mathrm{f}}=$ cost of fixed activity $\mathrm{f}$ (dollars)

$\mathrm{a}_{\mathrm{v}}=$ area affected by activity $\mathrm{v}$ (acres)

$\mathrm{p}_{\mathrm{v}}=$ effectiveness of activity $\mathrm{v}$ (dimensionless)

$l_{\mathrm{p}}=$ predicted land condition (dimensionless)

$l_{g}=$ land condition goal (dimensionless)

$\mathrm{v}=$ variable cost activities (dollars)

$\mathrm{f} \quad$ = fixed cost activities (dimensionless)

$\mathrm{n}=$ number of activities (dimensionless)

\section{ATTACC Cost Analysis Input Data Descriptions and Data Sources}

An inventory of land maintenance activities and costs is obtained from installation records. Areas affected by maintenance activities are obtained from published reports, installation records, and expert opinion. Effectiveness values $(\mathrm{P}$ factor) for land maintenance practices are obtained from published literature and expert opinion. 


\section{ATTACC Main Model Sensitivity Analysis}

Sensitivity analyses results are site specific. For this reason, two installations were selected for the sensitivity analysis based on availability of data and differences in environmental, cost, and training load characteristics. The installations selected were Fort Hood, Texas, and Combat Maneuver Training Center (CMTC), Hohenfels, Germany. Data used for the sensitivity analysis are based on data used in the ATTACC implementations for the installations (Concepts Analysis Agency 1996 a,b; Anderson et al. 1996).

In the sensitivity analysis of the overall ATTACC model, changes in land maintenance funding requirements are assessed based on changes in land condition, cost analysis, training load, and management goal input values. The land condition component includes all environmental variables associated with the development of the land condition curve. A change in the land condition input values results in a change in the land condition curve. The training load component includes all training impact factors and mileage estimates associated with the calculation of MIM. A change in a training load input value results in a change in the total MIM. The cost analysis component includes all variables associated with the development of cost analysis factors including costs, area affected, effectiveness, and mix of practices. A change in a cost analysis component input value results in a change in the cost of a 1 percent shift of the land condition curve and a change in the total land maintenance costs estimated.

\section{Fixed Input Variation Effects on Model Output}

A sensitivity analysis with fixed percentage changes in the input values was conducted for Fort Hood and CMTC Hohenfels. Fixed percentage changes in input are an increase or decrease in input values of a fixed percentage. The change in input is not based on an assessment of the uncertainty of the inputs or on differences in alternative input sources. This analysis demonstrates the sensitivity of model outputs on model inputs. The base case ( 0 percent change in input values) uses the same data used in the ATTACC implementation (Concepts Analysis Agency 1996 a,b; Anderson et al. 1996). 
Figures 3 through 6 show the effect of changes in cost, training load, land condition, and management goal data. Land maintenance costs were most sensitive to changes in the cost analysis component of the ATTACC model. A change in cost analysis component input resulted in an equivalent change in overall model output. Changes in management goal, land condition, and training load component inputs were similar. A percentage change in input values resulted in a smaller percentage change in overall model output.

Results of the sensitivity analysis were similar for Fort Hood and CMTC Hohenfels. However, the effect of changes in management goal, land condition, and training load components was relatively smaller for Fort Hood than CMTC Hohenfels. For the range of input values tested, model outputs were linearly related to model inputs.
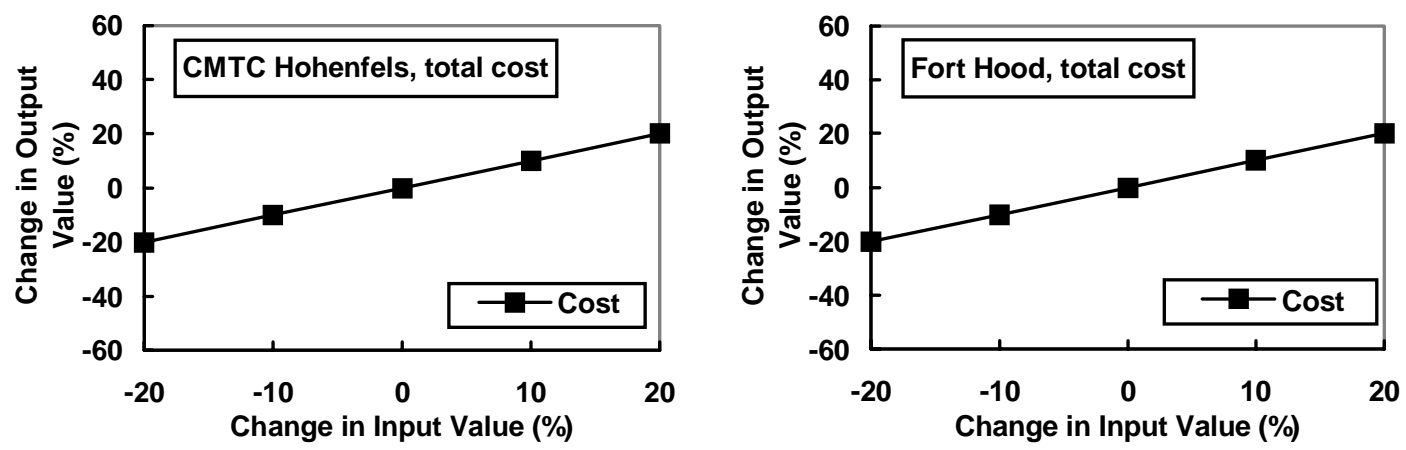

Figure 3. Effect of changes in total cost values on ATTACC model outputs.
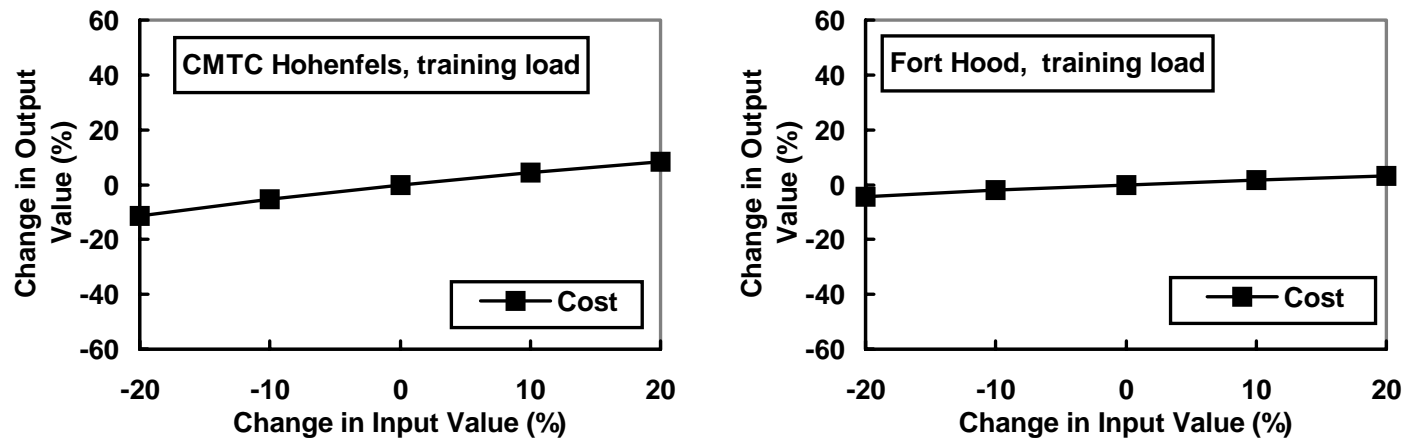

Figure 4. Effect of changes in training load values on ATTACC model outputs. 

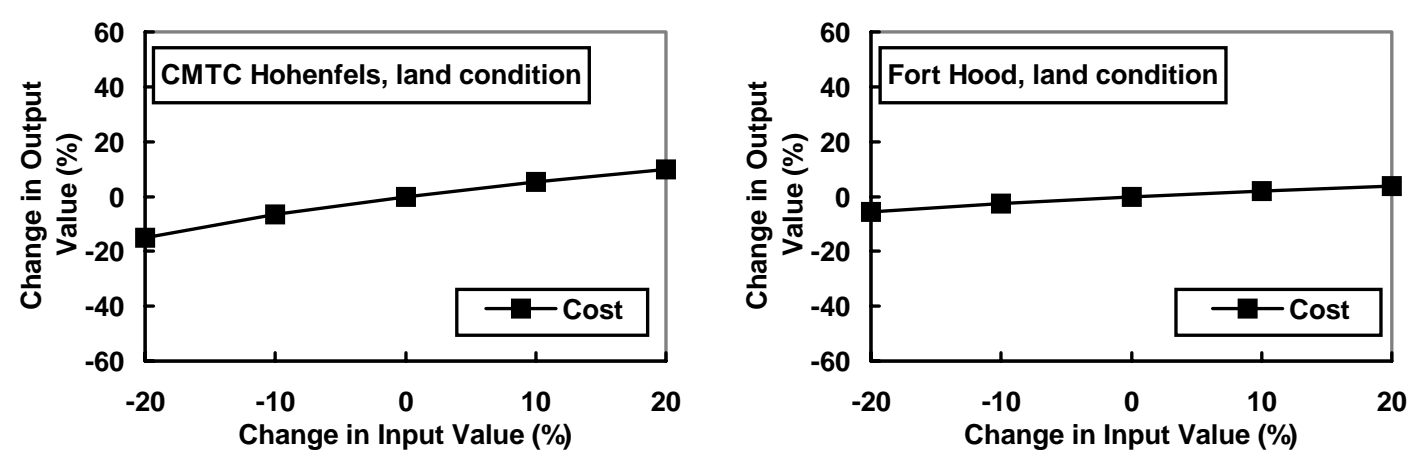

Figure 5. Effect of changes in land condition values on ATTACC model outputs.
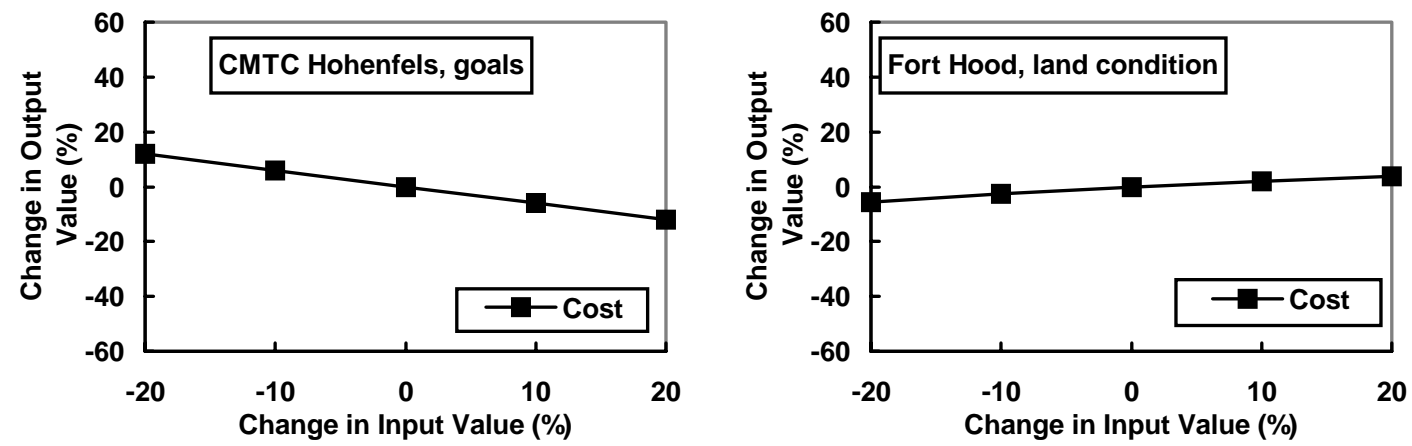

Figure 6. Effect of changes in management goals on ATTACC model outputs.

\section{Analysis of Variance of Fixed Input Effects on Model Output}

Two values were selected for each main model component input parameter: a 20 percent increase and a 20 percent decrease. For the 4 parameters evaluated, this resulted in 16 combinations of the parameter values. The analysis was conducted for Fort Hood and CMTC Hohenfels. The complete experiment is then 32 simulation runs.

Two statistical methods were used in evaluating the results of these simulation runs: ANOVA and probability plotting of squared contrasts. More detailed information on use of a factorial design in the sensitivity analysis of a simulation model is given in Box, Hunter, and Hunter (1978). The use of probability plots is further expanded in Gnanadesikan (1997).

For this analysis, the effects of the parameters are ranked with respect to each other. Since the study design is balanced, the sum of squares from the analysis of variance can be used. The sums of squares associated with these effects in the analysis of variance table are ordered by largest to smallest. There are 15 single-degree-of-freedom sums of squares. After sorting, these form a cumulative 
empirical distribution with associated probabilities. Under the null hypothesis of no effect, these sums of squares would be distributed as a chi-square. The sums of squares are plotted against the corresponding values for a chi-square distribution. Under the null hypothesis, the points should form a straight line. Departure from this trend indicates significant deviation from the hypothesis of no effect. The points that are greatly separated from the trend line (indicated by the other points) have the greatest effect on the model. This technique allows one to see the relative effect (squared) of each variable. Figure 7 shows the single degree of freedom sum of squares plotted against the chi-square distribution for each measure of land condition.

The main ATTACC model was most sensitive to changes in the cost analysis component. The main model was moderately sensitive to changes in the training characterization, environmental, and management goal components of the ATTACC model. There were no significant interactions between main components of the ATTACC model.

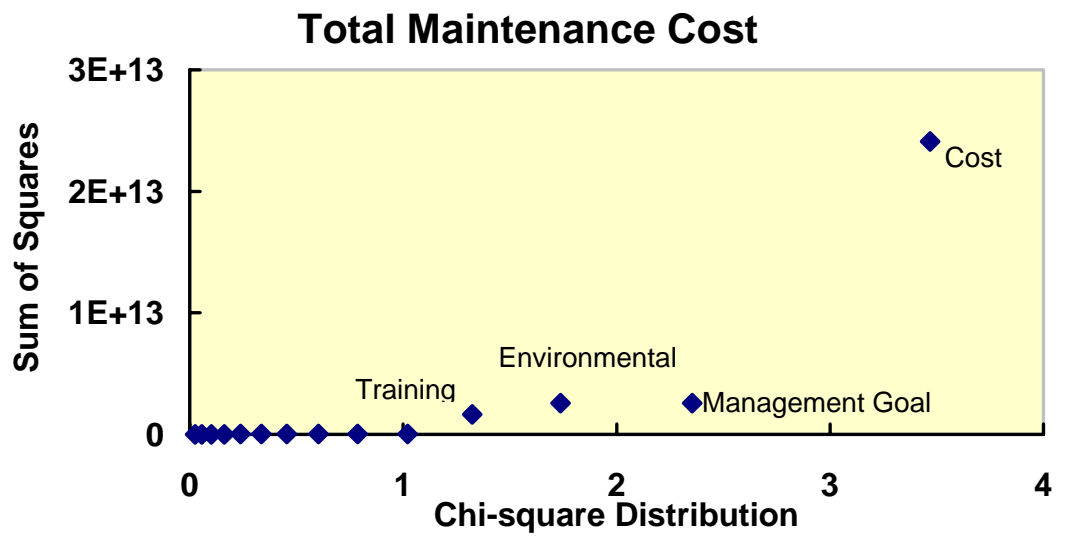

Figure 7. Single degree of freedom sum of squares plotted against the chi-square distribution for total maintenance cost.

\section{Average Linear Sensitivity Coefficient for ATTACC Main Model Input Variables}

The average linear sensitivity (S) coefficient for the change in model response relative to the values of input variables is defined in Equation 6. The S coefficient represents a relative normalized change in output to a normalized change in input, which allows a means of comparing sensitivities for input parameters that have different orders of magnitude. 


$$
S=\frac{\left(\frac{\left(o_{1}-o_{2}\right)}{o_{\overline{1,2}}}\right)}{\left(\frac{\left(i_{1}-i_{2}\right)}{i_{\overline{1,2}}}\right)}
$$

where:

$S \quad=$ normalized measure of sensitivity

$o_{1} \quad=$ output for input level 1

$O_{2} \quad=$ output for input level 2

$o_{1,2} \quad=$ average output for input levels 1 and 2

$i_{1} \quad=$ input for level 1

$i_{2} \quad=$ input for level 2

$i_{1,2} \quad=$ average input for levels 1 and 2

There are several limitations to using the $\mathrm{S}$ coefficient in as sensitivity analysis. First, the linear form of the sensitivity parameter does not reflect sensitivity over the entire range of the parameter if the relationship between the input and output is nonlinear. This is not a concern because most input variables in the environmental component of ATTACC are nearly linear in their relationship to model output values (see previous section). Secondly, the sensitivity parameter is a univariate parameter, which implies that there is no interaction between input variables. This also is not a concern because the input variables of ATTACC model do not have significant interactions.

Average S coefficient values were estimated for the overall ATTACC model input parameters (Table 1). A positive $S$ coefficient value means that an increase in the input value results in an increase in the model output and that a decrease in the input value results in a decrease in the model output. A negative S coefficient value means an increase in model input is associated with a decrease in model output and a decrease in the model input is associated with an increase in the model output. An $\mathrm{S}$ value of 1 means that a change in input value results in a proportional change in model output. A value of less than 1 indicates a proportionately smaller change in model output than in model input. The ATTACC model is most sensitive to changes in the cost analysis component (Table 1). 
Table 1. Sensitivity coefficient (S) of ATTACC input variables.

\begin{tabular}{|l|r|r|}
\hline \multirow{2}{*}{ Variable } & \multicolumn{2}{|c|}{ Sensitivity of Cost } \\
\cline { 2 - 3 } & Hohenfels & \multicolumn{1}{c|}{ Hood } \\
\hline Cost & 1.000 & 1.000 \\
Training Load & 0.501 & 0.189 \\
Land Condition & 0.641 & 0.234 \\
Management Goal & -0.600 & -0.223 \\
\hline
\end{tabular}




\section{ATTACC Training Characterization Component Sensitivity Analysis}

In the sensitivity analysis of the training component of the ATTACC model, the effect of changes in training load (MIM) are assessed based on changes in annual mileage, vehicle severity factor (VSF), event severity factor (ESF), vehicle offroad factor (VOF), and vehicle conversion factor (VCF). These are the main input variables of the training component.

Changes in land condition measures associated with changes in training component input factors were also included in the sensitivity analysis. Average ES is the current measure of land condition in the ATTACC model. However, percentage of land with ES greater than a selected value has also been proposed as an alternative standard. Average ES, percentage of lands with ES greater than 1, and percentage of lands with ES greater than 2 were used as land condition measures. The land condition curve for each installation was used to evaluate the effect of changes in training load on predicted land condition.

\section{Fixed Input Variation Effects on Model Output}

A sensitivity analysis with fixed percentage changes in the input values was conducted for Fort Hood and CMTC Hohenfels. This analysis shows the sensitivity of ATTACC training load component outputs to model inputs. The base case ( 0 percent change in input values) is the actual data used in the ATTACC implementation.

Figures 8 through 12 show the effect of changes in annual mileage, VSF, ESF, VOF, and VCF on land condition output values. Training load was equally sensitive to all input factors. A percentage change in input values resulted in an equivalent percentage change in training load. This is because the equation for training load calculation is a multiplication of each of the individual training load impact factors and annual mileage estimates.

Results were different for Fort Hood and CMTC Hohenfels. For CMTC Hohenfels, percent lands with ES greater than 2 was more sensitive than percent lands 
with ES greater than 1 which was more sensitive than average ES to model inputs. Land condition measures for CMTC Hohnenfels were generally more sensitive than MIMs to training load component input values. For Fort Hood, average ES was more sensitive than ES greater then 2 was more sensitive than percent of with ES greater than 1. Land condition measures at Fort Hood were less sensitive than MIMs to training load inputs. The differences in results are related to the different distributions of ES values for each installation. For the range of input values tested, model outputs were linearly related to model inputs.
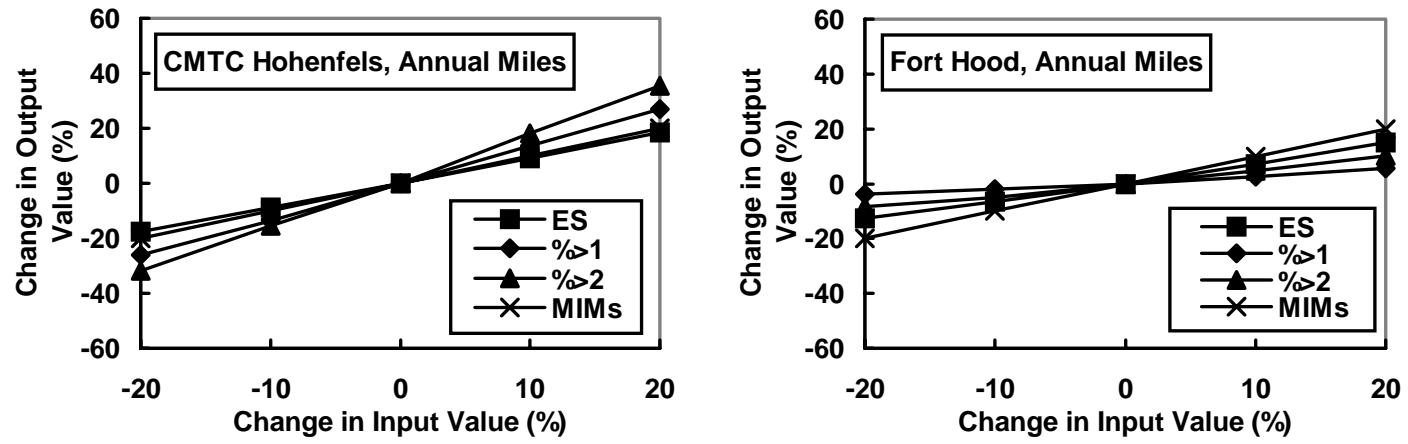

Figure 8. Effect of changes in annual mileage estimates on training load factor estimates and on ATTACC model outputs.
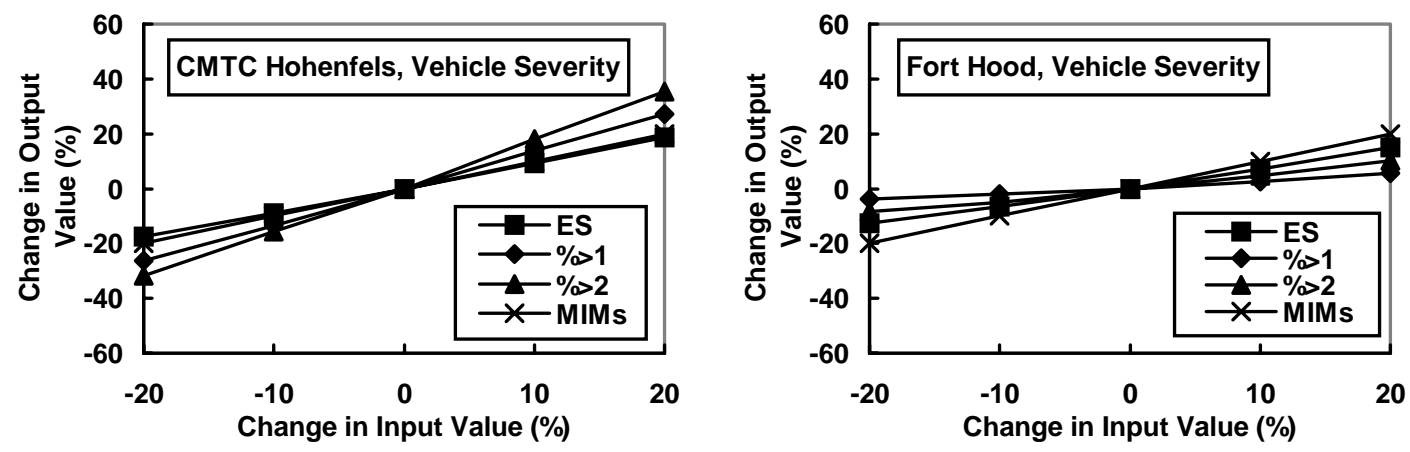

Figure 9. Effect of changes in vehicle severity factors values on training load factor estimates and on ATTACC model outputs. 

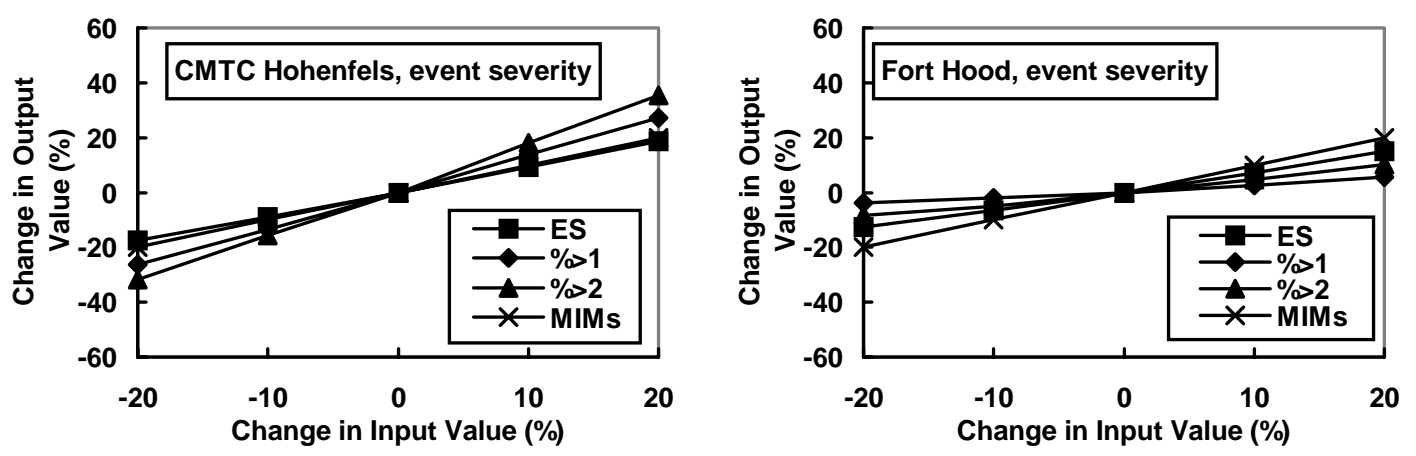

Figure 10. Effect of changes in event severity factor values on training load factor estimates and on ATTACC model outputs.
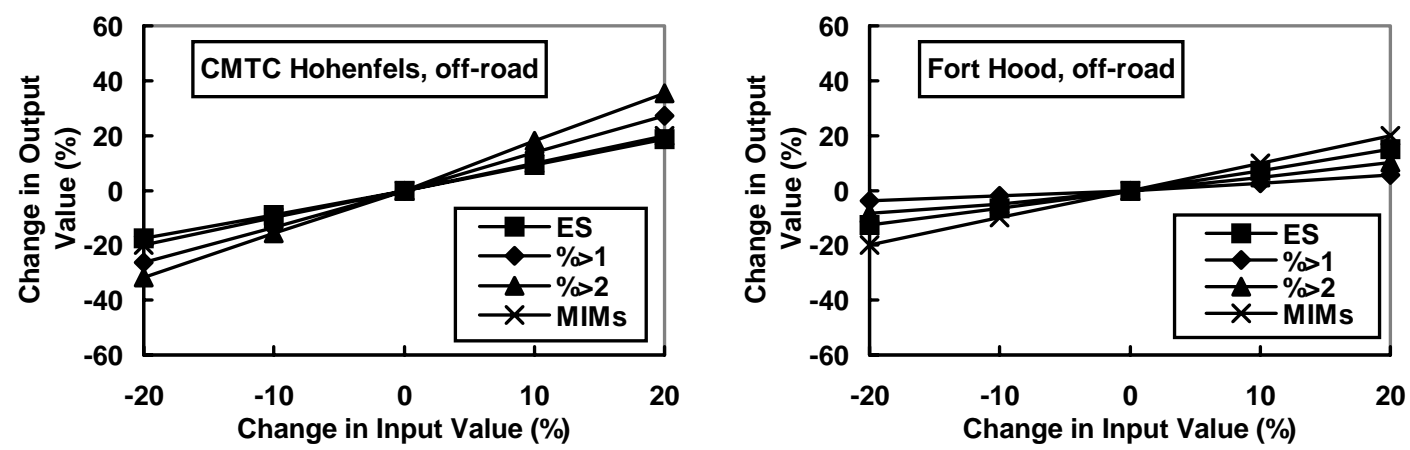

Figure 11. Effect of changes in vehicle off-road factor values on training load factor estimates and on ATTACC model outputs.
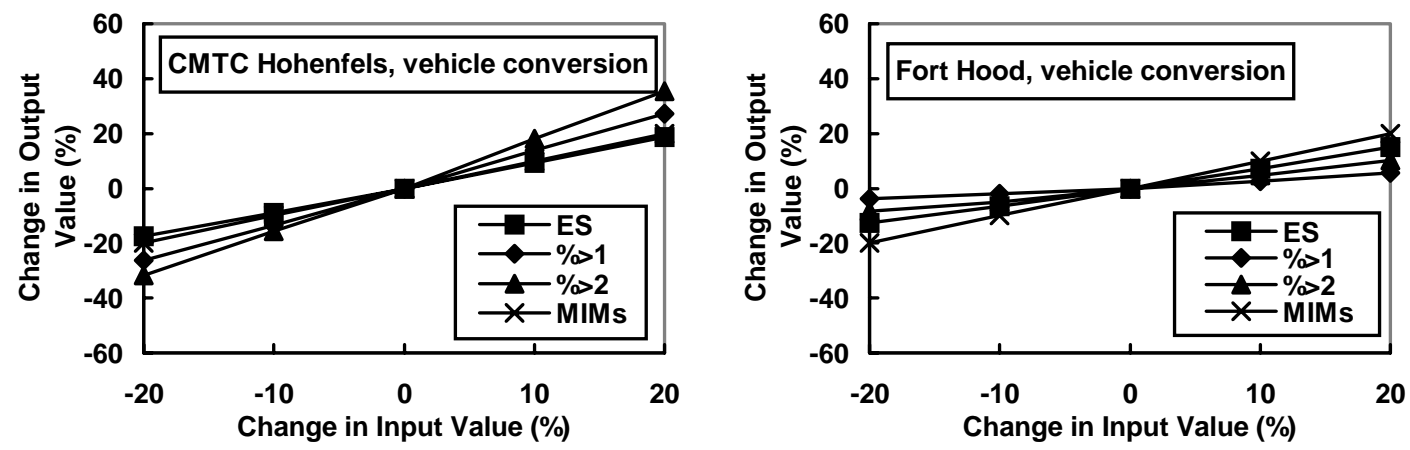

Figure 12. Effect of changes in vehicle conversion factor values on training load factor estimates and on ATTACC model outputs.

\section{Analysis of Variance of Fixed Input Effects on Model Output}

Two values were selected for each training component input parameter: a 20 percent increase and a 20 percent decrease. For the 4 parameters evaluated, this resulted in 16 combinations of the parameter values. The analysis was con- 
ducted for Fort Hood and CMTC Hohenfels. The complete experiment is then 32 simulation runs.

Two statistical methods were used in evaluating the results of these simulation runs: ANOVA and probability plotting of squared contrasts. The sums of squares are plotted against the corresponding values for a chi-square distribution. Under the null hypothesis, the points should form a straight line. Departure from this trend indicates significant deviation from the hypothesis of no effect. The points that are greatly separated from the trend line (indicated by the other points) have the greatest effect on the model. Figure 13 shows the single degree of freedom sum of squares plotted against the chi-square distribution for each model output.

The input parameters Annual Miles, ESF, VSF, VOF, and VCF input values had the largest effect on all model outputs. There were no significant interactions be-tween input variables for normalized training load (MIM) or any of the measures of land condition.
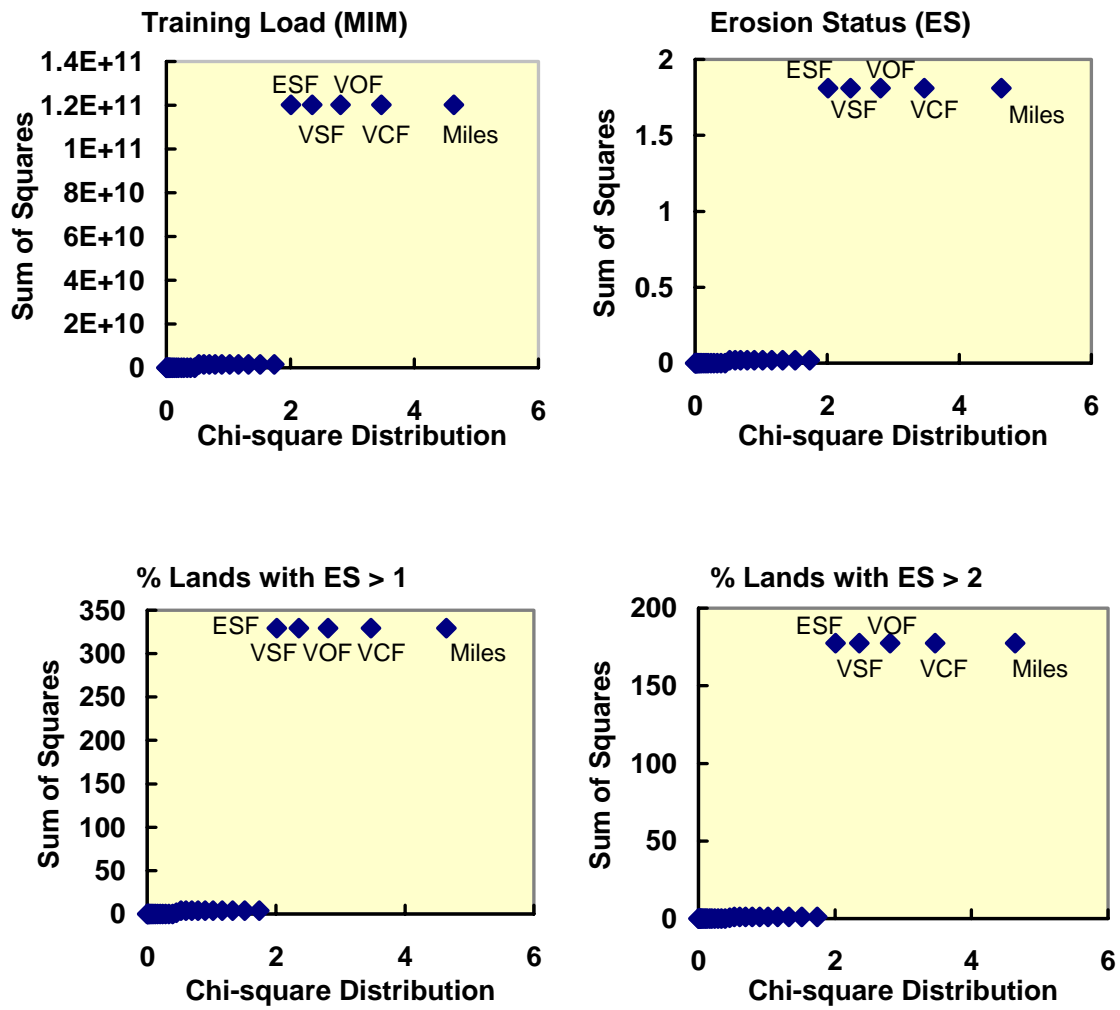

Figure 13. Single degree of freedom sum of squares plotted against the chi-square distribution for training load, average erosion status, percent lands with ES greater than 1, and percent lands with ES greater than 2. 


\section{Average Linear Sensitivity Coefficient for ATTACC Training Load Component Input Variables}

Average S coefficient values were estimated for the ATTACC training characterization component input parameters (Table 2). The training characterization component of the ATTACC model is equally sensitive to all input parameters. However, the model was more sensitive to changes to input values at CMTC Hohenfels than at Fort Hood. The alternative measures of land condition (percent of lands with ES greater than 1 or 2) were more sensitive to changes in input values than the current measure of land condition (average ES) at Fort Hood. For CMTC Hohenfels, average ES was less sensitive to changes in input values than the other measures of land condition.

Table 2. Sensitivity (S) coefficient values for training characterization component input variables.

\begin{tabular}{|l|r|r|r|r|r|r|r|r|}
\hline \multirow{2}{*}{ Variable } & \multicolumn{2}{|l|}{ Sensitivity of MIMs } & \multicolumn{2}{c|}{$\begin{array}{c}\text { Sensitivity of } \\
\text { Average ES }\end{array}$} & \multicolumn{2}{c|}{$\begin{array}{c}\text { Sensitivity of \% } \\
\text { lands with ES > }\end{array}$} & \multicolumn{2}{c|}{$\begin{array}{c}\text { Sensitivity of \% } \\
\text { lands with ES > 2 }\end{array}$} \\
\cline { 2 - 10 } & Hohenfels & Hood & Hohenfels & Hood & Hohenfels & Hood & Hohenfels & Hood \\
\hline Miles & 1.000 & 1.000 & 0.907 & 0.699 & 1.339 & 0.235 & 1.710 & 0.468 \\
\hline VSF & 1.000 & 1.000 & 0.907 & 0.699 & 1.339 & 0.235 & 1.710 & 0.468 \\
\hline ESF & 1.000 & 1.000 & 0.907 & 0.699 & 1.339 & 0.235 & 1.710 & 0.468 \\
\hline VOF & 1.000 & 1.000 & 0.907 & 0.699 & 1.339 & 0.235 & 1.710 & 0.468 \\
\hline VCF & 1.000 & 1.000 & 0.907 & 0.699 & 1.339 & 0.235 & 1.710 & 0.468 \\
\hline
\end{tabular}




\section{ATTACC Environmental Component Sensitivity Analysis}

The primary environmental input parameters of the ATTACC environmental component include: initial vegetative cover $(\mathrm{C})$, change in cover due to mission activity, (impact) soil erodibility (K), land topography (LS), soil loss tolerance (T), climate $(\mathrm{R})$, management practices $(\mathrm{P})$, land recovery, maximum $\mathrm{C}$ value, shape of the recovery curve, shape of the impact curve, and training load. Changes in land condition measures associated with changes in training component input factors were also included in the sensitivity analysis.

Average ES is the current measure of land condition in the ATTACC model. However, percentage of land with ES greater than a selected value has also been proposed as an alternative standard. Average ES, percentage of lands with ES greater than 1, and percentage of lands with ES greater than 2 were used as land condition measures.

\section{Fixed Input Variation Effects on Model Output}

A sensitivity analysis with fixed percentage changes in the input values was conducted for Fort Hood and CMTC Hohenfels. This analysis shows the sensitivity of ATTACC environmental component outputs to model inputs. The base case ( 0 percent change in input values) is the actual data used in the ATTACC implementation.

Figures 14 through 26 show the effect of changes in ATTACC environmental component input values on land condition output values. For both installations, the K, LS, T, P, and R input values had the largest effect on model outputs for all measures of land condition. Model outputs were moderately sensitive to training load (MIMs), impact, recovery, shape of recovery curve, and shape of the impact curve factors. Model output was relatively insensitive to initial vegetative cover. A percentage change in input values resulted in a relatively larger change in land condition for CMTC Hohenfels than for Fort Hood. 
Results were different for Fort Hood and CMTC Hohenfels for the different measures of land condition. For CMTC Hohenfels, percent lands with ES greater then 2 was more sensitive than percent of lands with ES greater than 1 which was more sensitive than average ES to changes in model inputs. For Fort Hood, average ES was more sensitive than ES greater then 2 was more sensitive than percent of with ES greater than 1. The differences in results for the two installations are related to the different distributions of ES values for each installation. For the range of input values tested, model outputs were linearly related to model inputs except for maximum $\mathrm{C}$ factor value.
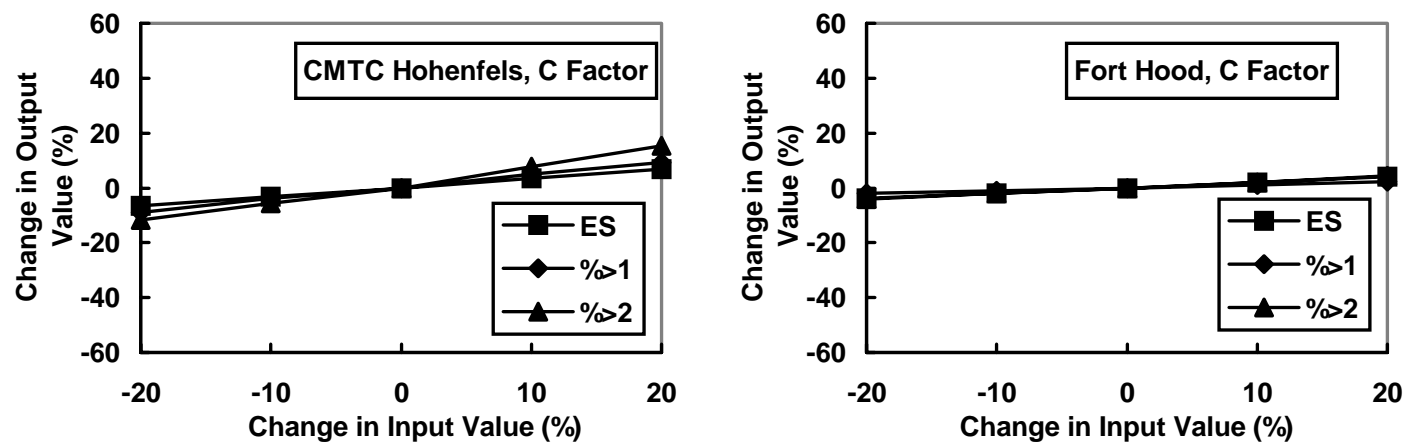

Figure 14. Effect of changes in C factor input values on ATTACC model outputs.
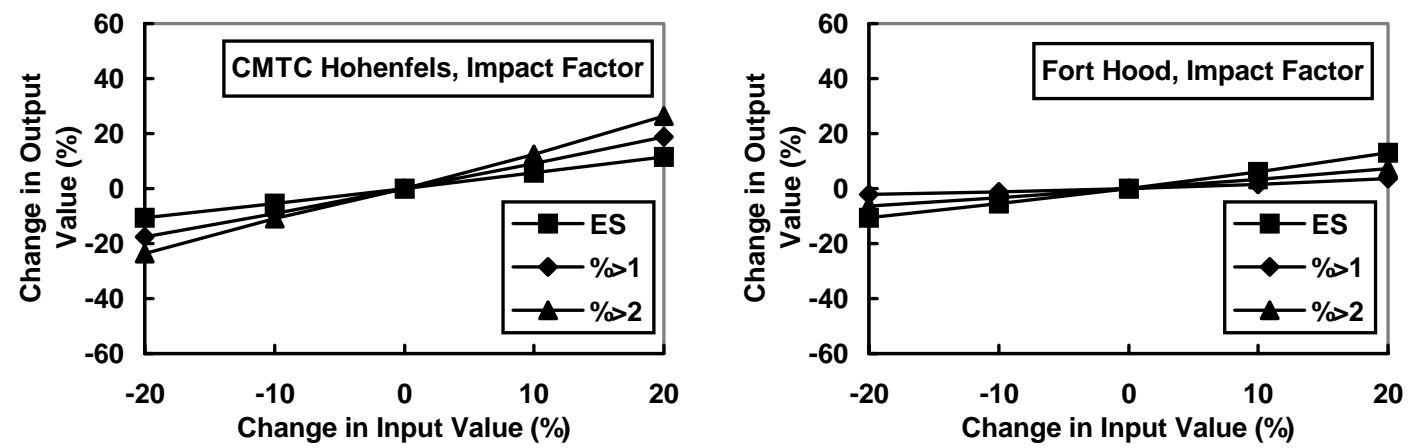

Figure 15. Effect of changes in impact factor input values on ATTACC model outputs.
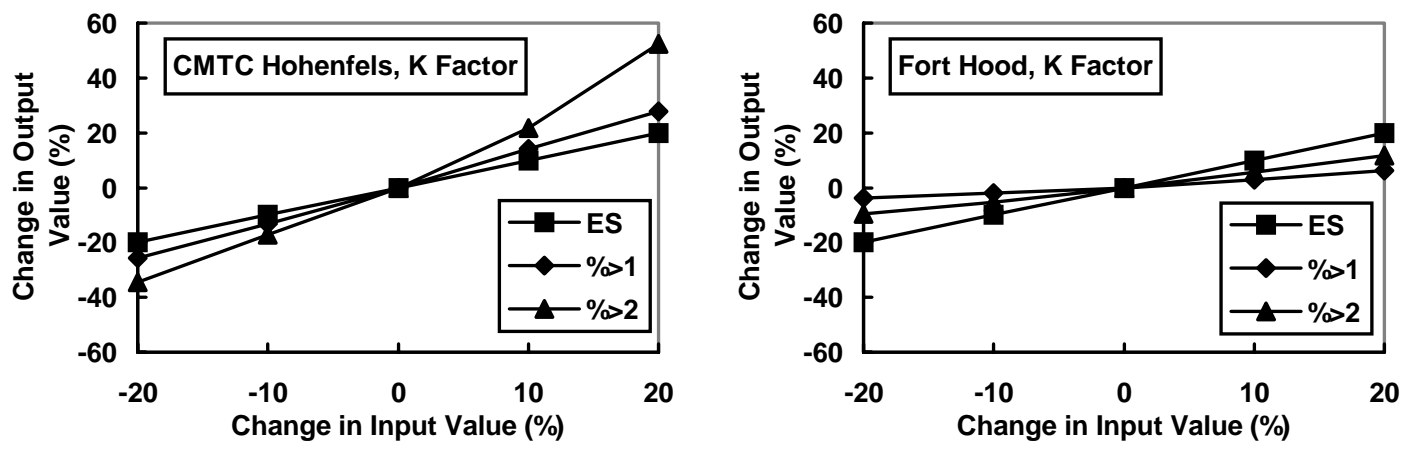

Figure 16. Effect of changes in $\mathrm{K}$ factor input values on ATTACC model outputs. 

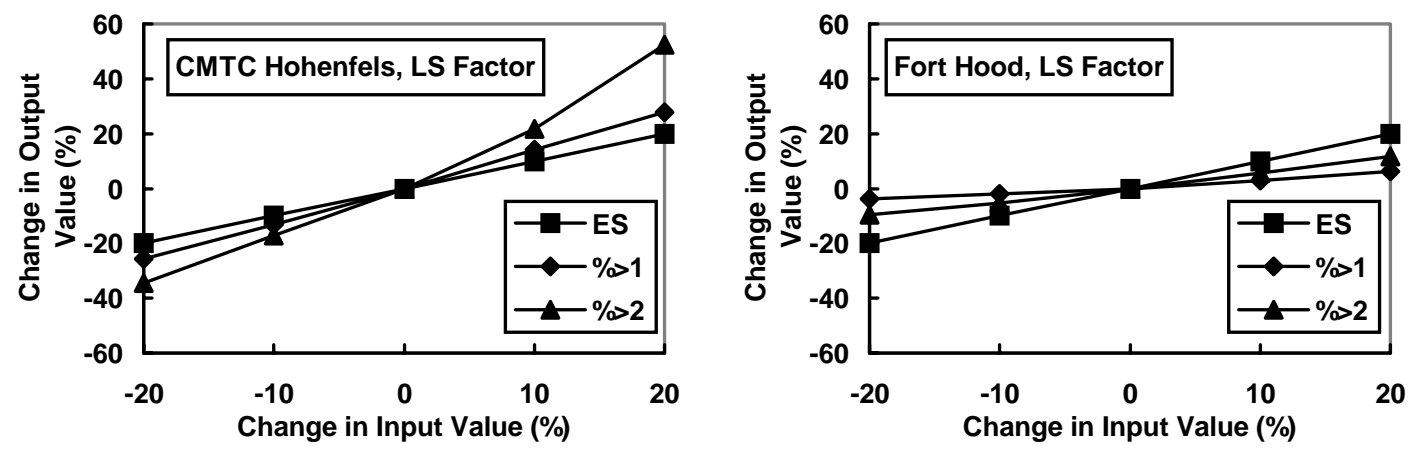

Figure 17. Effect of changes in LS factor input values on ATTACC model outputs.
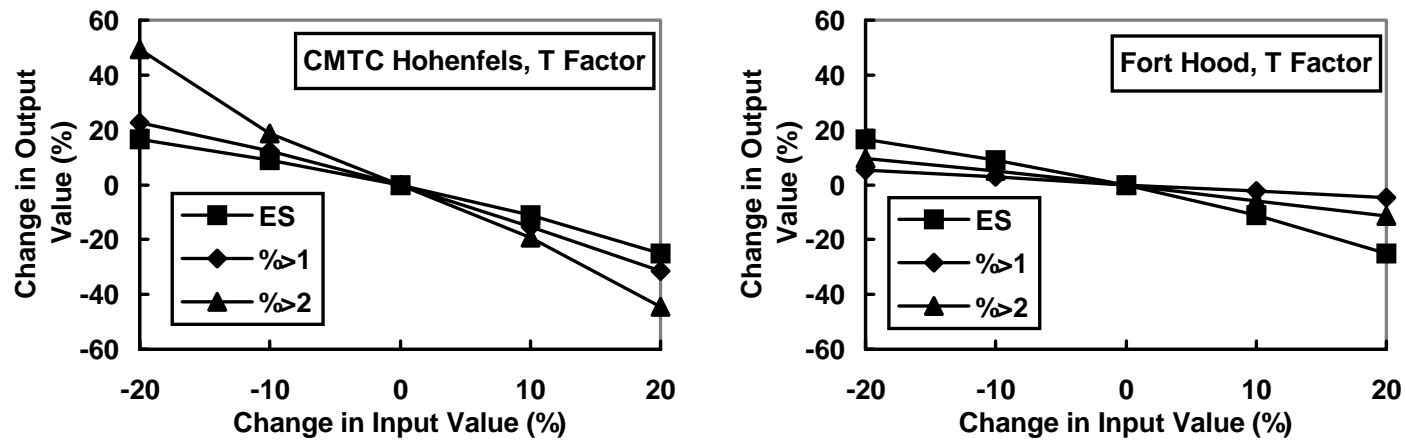

Figure 18. Effect of changes in T factor input values on ATTACC model outputs.
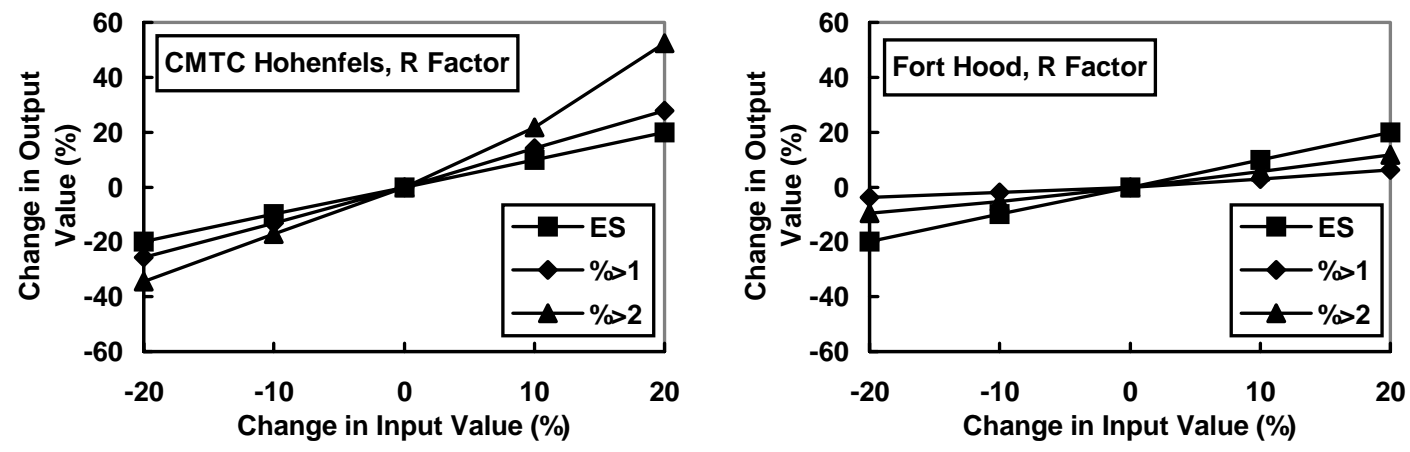

Figure 19. Effect of changes in R factor input values on ATTACC model outputs.
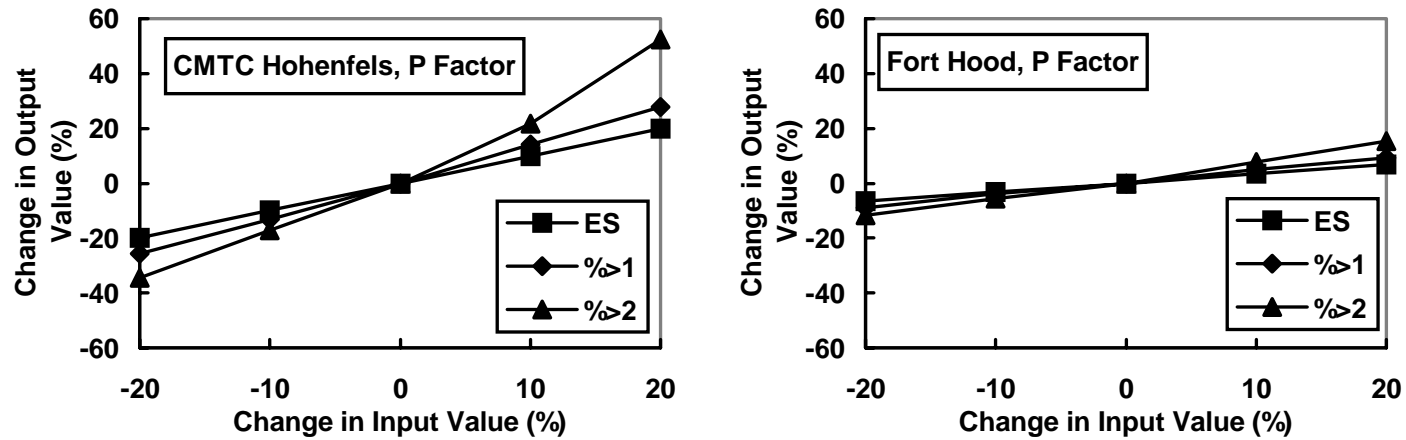

Figure 20. Effect of changes in P factor input values on ATTACC model outputs. 

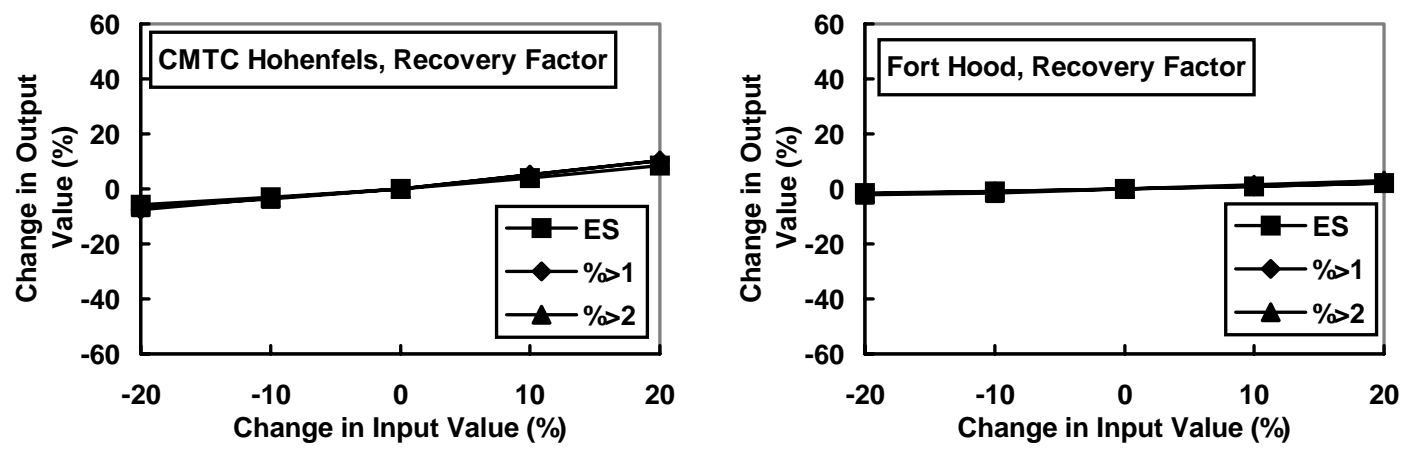

Figure 21. Effect of changes in recovery factor input values on ATTACC model outputs.
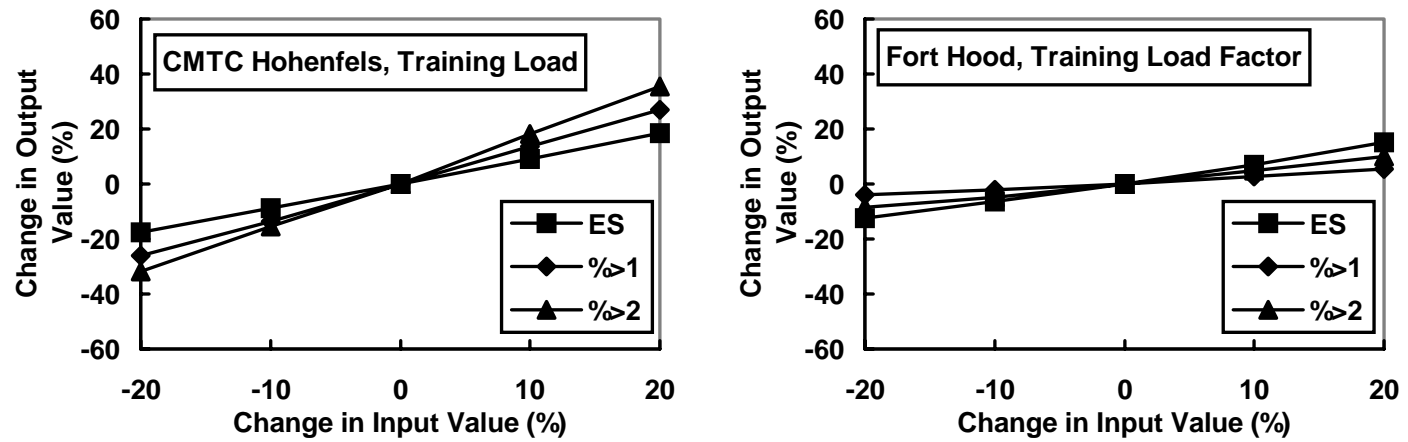

Figure 22. Effect of changes in training load factor input values on ATTACC model outputs.
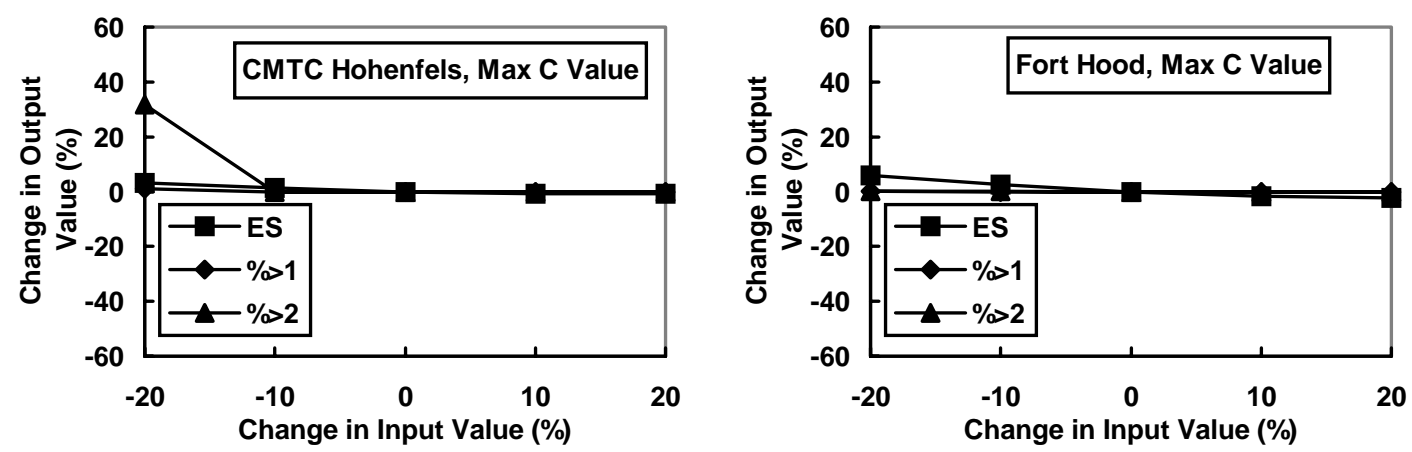

Figure 23. Effect of changes in maximum $\mathrm{C}$ factor parameter values on ATTACC model outputs.
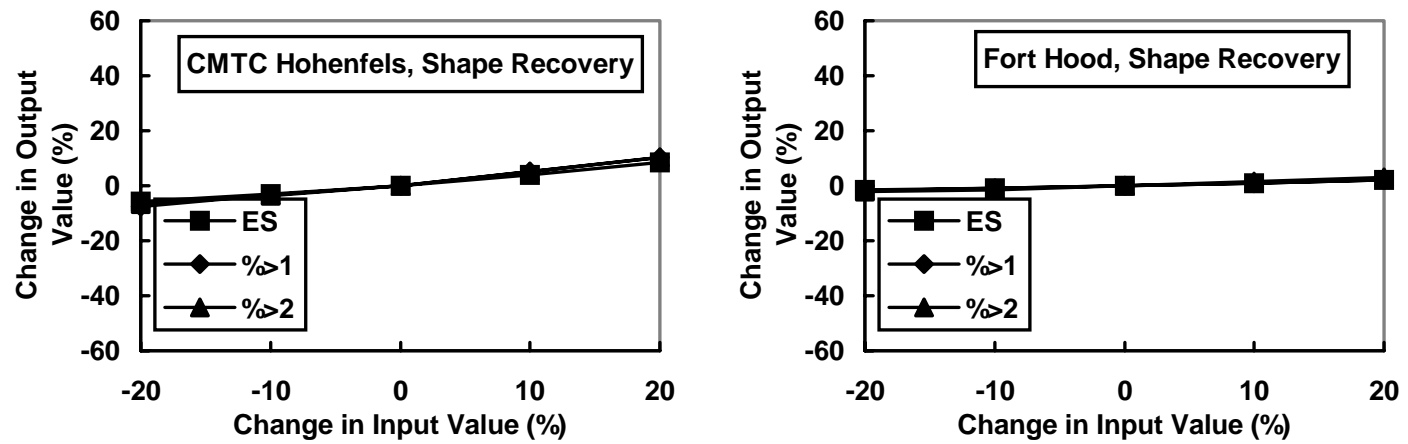

Figure 24. Effect of changes in shape of recovery factor curve on ATTACC model outputs. 

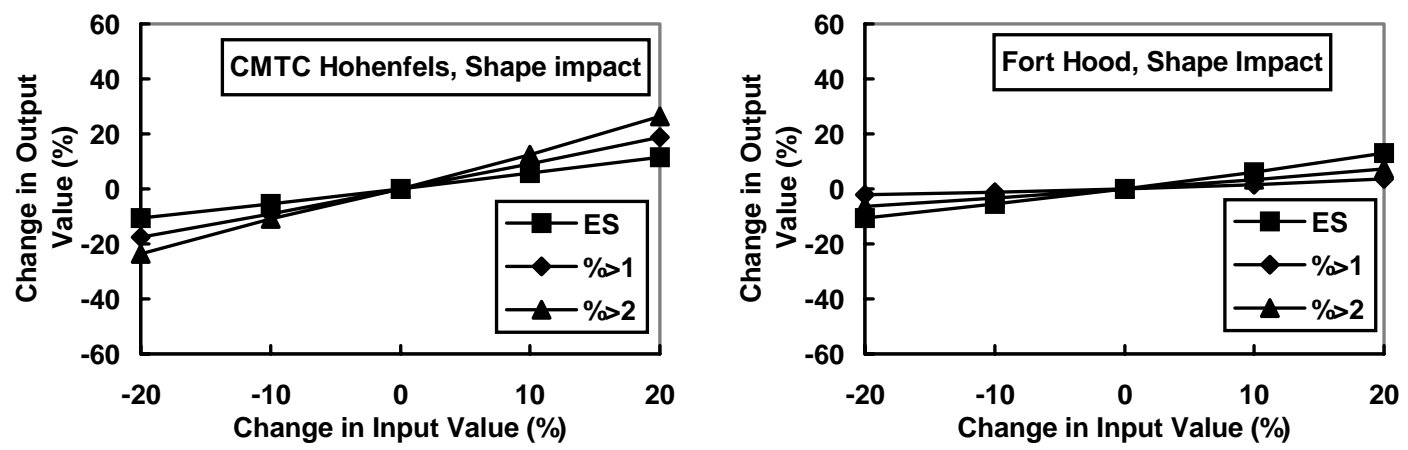

Figure 25. Effect of changes in shape of impact factor curve on ATTACC model outputs.
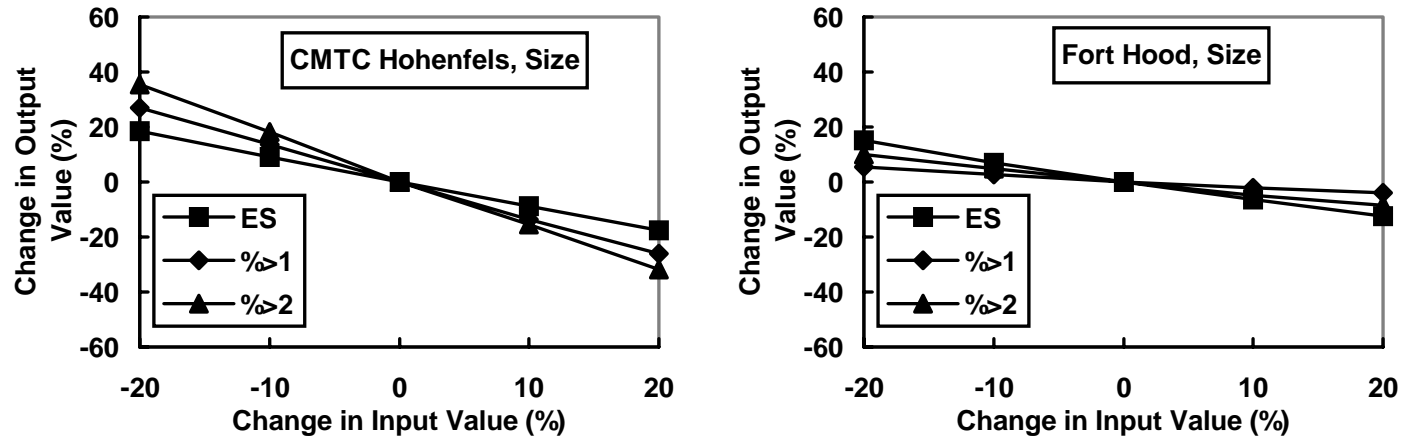

Figure 26. Effect of changes in net maneuver area on ATTACC model outputs.

\section{Analysis of Variance of Fixed Input Effects on Model Output}

Two values were selected for each environmental component input parameter: a 20 percent increase and a 20 percent decrease. For the 8 parameters evaluated, this resulted in 256 combinations of the parameter values. The analysis was conducted for Fort Hood and CMTC Hohenfels. The complete experiment is then 512 simulation runs.

Two statistical methods were used in evaluating the results of these simulation runs: ANOVA and probability plotting of squared contrasts. For this analysis the effects of the parameters are ranked with respect to each other. The sums of squares are plotted against the corresponding values for a chi-square distribution. Under the null hypothesis, the points should form a straight line. Departure from this trend indicates significant deviation from the hypothesis of no effect. The points that are greatly separated from the trend line (indicated by the other points) have the greatest effect on the model. Figure 27 shows the single degree of freedom sum of squares plotted against the chi-square distribution for each measure of land condition. 
The input parameters K, LS, T, and R had the largest effect on model outputs for all measures of land condition. Model outputs were moderately sensitive to training load (MIM), impact, and recovery factors. There were no significant interactions between input variables for any of the measures of land condition.
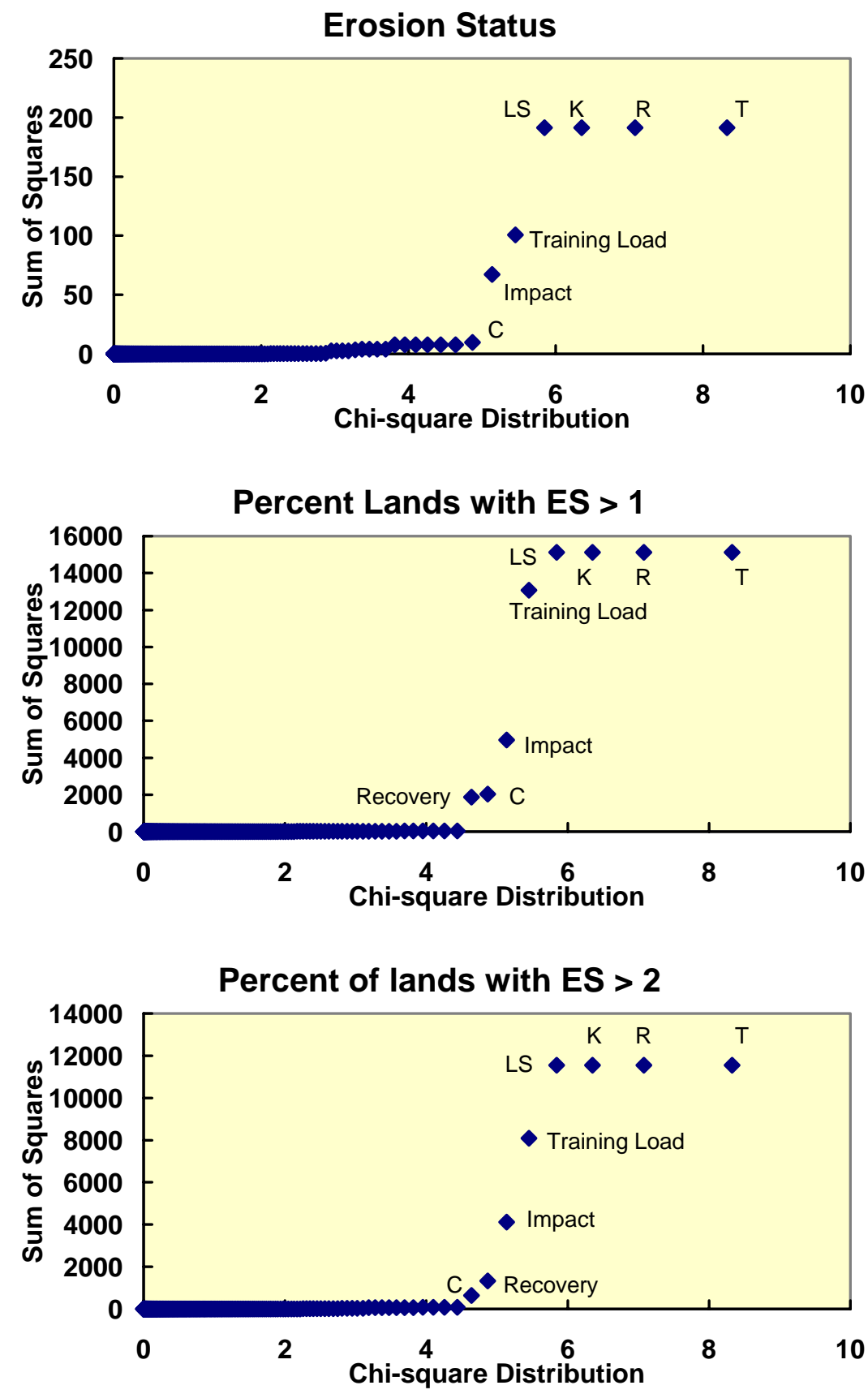

Figure 27. Single degree of freedom sum of squares plotted against the chi-square distribution for average erosion status, percent lands with ES greater than 1, and percent lands with ES greater than 2. 


\section{Average Linear Sensitivity Coefficient for ATTACC Environmental Component Input Variables}

Average linear sensitivity coefficient (S) values were estimated for the ATTACC environmental component input parameters (Table 3). Average ES was less sensitive to changes in input parameters than the other measures of land condition. CMTC Hohenfels was more sensitive to changes in input values than Fort Hood.

Table 3. Sensitivity coefficient (S) values for environmental component input variables.

\begin{tabular}{|l|c|c|c|c|c|c|}
\hline & \multicolumn{2}{|c|}{$\begin{array}{c}\text { Sensitivity of } \\
\text { average ES }\end{array}$} & \multicolumn{2}{c|}{$\begin{array}{c}\text { Sensitivity of \% } \\
\text { lands with ES > 1 }\end{array}$} & \multicolumn{2}{c|}{$\begin{array}{c}\text { Sensitivity of \% lands } \\
\text { with ES > 2 }\end{array}$} \\
\hline Variable & Hohenfels & Hood & Hohenfels & Hood & Hohenfels & Hood \\
\hline MIMs & 0.907 & 0.699 & 1.339 & 0.235 & 1.710 & 0.468 \\
\hline K & 1.000 & 1.000 & 1.356 & 0.255 & 2.389 & 0.540 \\
\hline T & -1.000 & -1.000 & -1.300 & -0.252 & -2.404 & -0.523 \\
\hline LS & 1.000 & 1.000 & 1.356 & 0.255 & 2.389 & 0.540 \\
\hline C & 0.336 & 0.197 & 0.451 & 0.103 & 0.685 & 0.207 \\
\hline R & 1.000 & 1.000 & 1.356 & 0.255 & 2.389 & 0.540 \\
\hline Impact & 0.558 & 0.604 & 0.911 & 0.149 & 1.269 & 0.346 \\
\hline Rec & 0.361 & 0.095 & 0.456 & 0.099 & 0.430 & 0.132 \\
\hline P & 1.000 & 0.211 & 1.356 & 0.001 & 2.389 & 0.004 \\
\hline MaxC & 0.100 & 1.000 & 0.029 & 0.255 & 0.947 & 0.540 \\
\hline Net Area & -0.907 & -0.699 & -1.339 & -0.235 & -1.710 & -0.468 \\
\hline Shape Rec & 0.361 & 0.095 & 0.456 & 0.099 & 0.430 & 0.132 \\
\hline Shape Impact & 0.558 & 0.604 & 0.911 & 0.149 & 1.269 & 0.346 \\
\hline
\end{tabular}




\section{ATTACC Cost Analysis Component Sensitivity Analysis}

In the sensitivity analysis of the cost analysis component of the ATTACC model, the effect of changes in variable costs, fixed costs, area affected, and effectiveness on model outputs were evaluated. These are the main input variables of the cost analysis component of the ATTACC model.

\section{Fixed Input Variation Effects on Model Output}

A sensitivity analysis with fixed percentage changes in the input values was conducted for Fort Hood and CMTC Hohenfels. This analysis shows the sensitivity of ATTACC cost analysis component outputs to model inputs. The base case ( 0 percent change in input values) is the actual data used in the ATTACC implementation.

Figures 28 through 31 show the effect of changes in variable costs, fixed costs, area affected, and effectiveness on land maintenance funding requirements output values. For CMTC Hohenfels, funding requirements were most sensitive to changes in effectiveness. Funding requirements were moderately sensitive to area affected and variable costs. Funding requirements were insensitive to changes in fixed costs. For Fort Hood, funding requirements were moderately sensitive to changes in area affected, effectiveness, and variable costs. Funding requirements were insensitive to changes in fixed costs. For the range of input values tested, model outputs were linearly related to model inputs. 

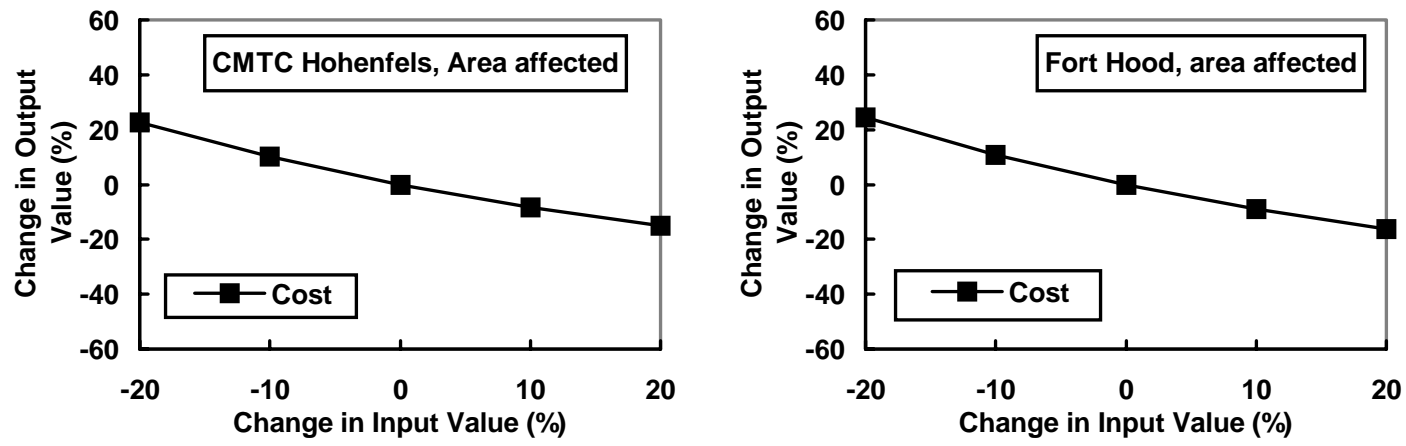

Figure 28. Effect of changes in repair practice area affected values on ATTACC model outputs.
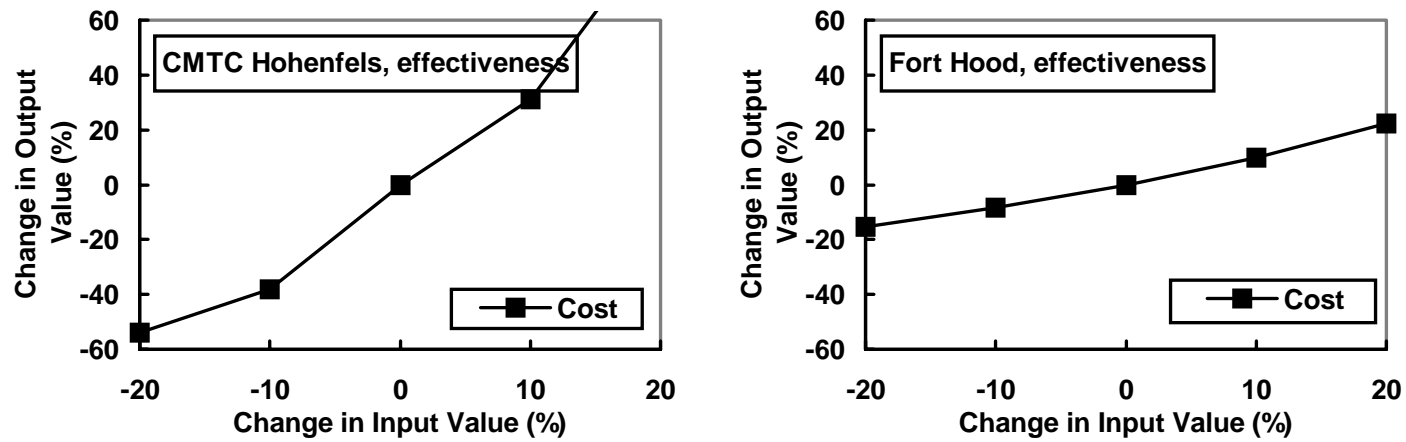

Figure 29. Effect of changes in land repair effectiveness values on ATTACC model outputs.
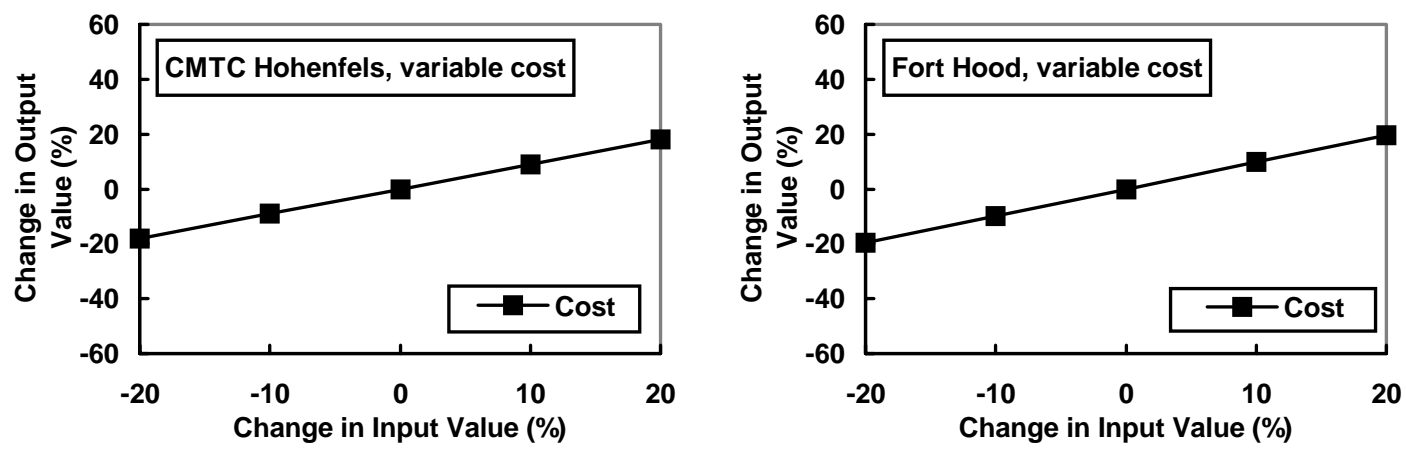

Figure 30. Effect of changes in variable costs values on ATTACC model outputs.
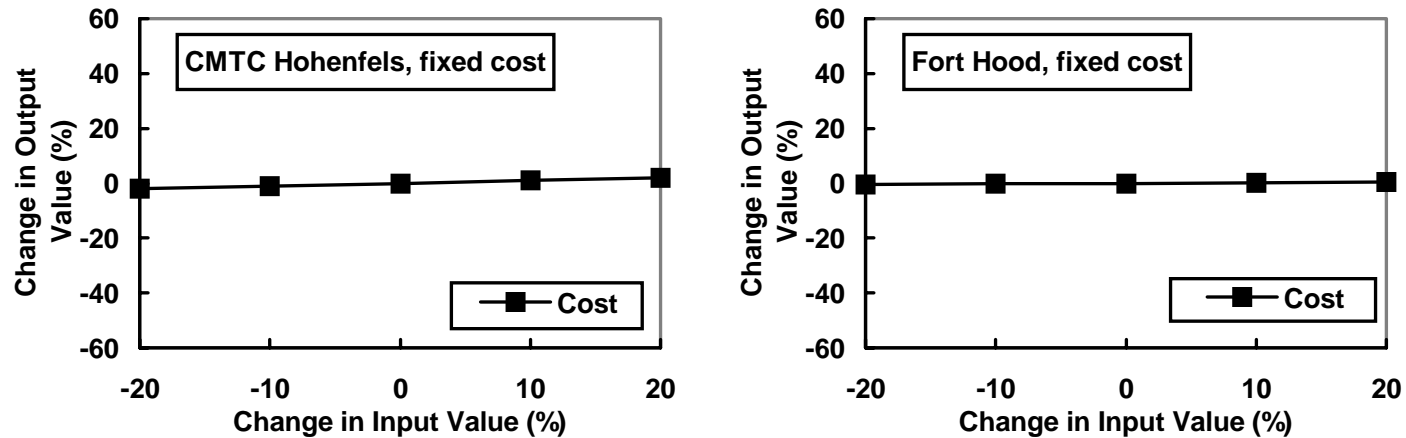

Figure 31. Effect of changes in fixed cost values on ATTACC model outputs. 


\section{Analysis of Variance of Fixed Input Effects on Model Output}

Two values were selected for each cost analysis component input parameter: a 20 percent increase and a 20 percent decrease. For the 4 parameters evaluated, this resulted in 16 combinations of the parameter values. The analysis was conducted for Fort Hood and CMTC Hohenfels. The complete experiment is then 32 simulation runs.

Two statistical methods were used in evaluating the results of these simulation runs: ANOVA and probability plotting of squared contrasts. For this analysis the effects of the parameters are ranked with respect to each other. The sums of squares are plotted against the corresponding values for a chi-square distribution. Under the null hypothesis, the points should form a straight line. Departure from this trend indicates significant deviation from the hypothesis of no effect. The points that are greatly separated from the trend line (indicated by the other points) have the greatest effect on the model. Figure 32 shows the single degree of freedom sum of squares plotted against the chi-square distribution.

The input parameters variable costs, acres affected, and practice effectiveness input values had the largest effect on model output. There were no significant interactions between input variables.

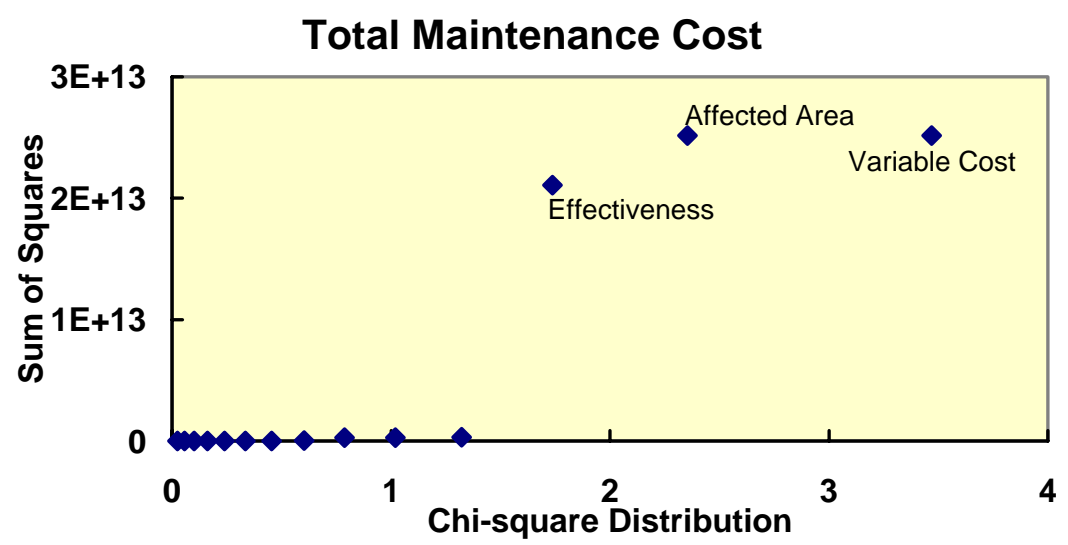

Figure 32. Single degree of freedom sum of squares plotted against the chi-square distribution for total maintenance cost. 


\section{Average Linear Sensitivity Coefficient for ATTACC Cost Analysis Component Input Variables}

Average linear sensitivity coefficient $(\mathrm{S})$ values were estimated for the ATTACC environmental component input parameters (Table 4). Total land maintenance funding requirement was most sensitive to changes in practice effectiveness, area affected and variable cost. The model was insensitive to changes in fixed costs. Results were similar between CMTC Hohenfels and Fort Hood. However, CMTC Hohenfels was much more sensitive to changes in practice effectiveness.

Table 4. Sensitivity coefficient (S) values for training characterization component input variables.

\begin{tabular}{|l|r|r|}
\hline \multirow{2}{*}{ Variable } & \multicolumn{2}{|c|}{ Sensitivity of Cost } \\
\cline { 2 - 3 } & Hohenfels & \multicolumn{1}{c|}{ Hood } \\
\hline Area Affected & -0.911 & -0.982 \\
\hline Effectiveness & 3.083 & 0.908 \\
\hline Variable Cost & 0.908 & 0.981 \\
\hline Fixed Cost & 0.092 & 0.019 \\
\hline
\end{tabular}




\section{Conclusions and Recommendations}

The ATTACC model was most sensitive to changes in the cost analysis component input values. The cost analysis component was most sensitive to changes in effectiveness, variable costs, and area affected. The ATTACC model was moderately sensitive to changes in the training characterization and environmental components input values. The training characterization component was equally sensitive to all training load input parameters. The environmental component was most sensitive to changes in K, LS, T, R, training load, and net training area. The environmental component was moderately sensitive to changes in the impact factor.

There were many similarities in results between the two installations tested. As a consequence, the results of this study should be generally applicable to other installations. Results of this study should prove useful in addressing ATTACC implementation issues including prioritizing data collection and ac-quisition at a MACOM or HQDA level.

Some differences in results between the two installations tested were evident. As the ATTACC model is implemented at installations, personnel may want to conduct similar sensitivity analyses using installation-specific data to assist in evaluating implementation issues such as alternate data sources and data quality. 


\section{Acronyms and Variables}

\begin{tabular}{|c|c|}
\hline ANOVA & Analysis of Variance \\
\hline ASA (IL\&E) & $\begin{array}{l}\text { Assistant Secretary of the Army for Installations Logistics and } \\
\text { Environment }\end{array}$ \\
\hline ASIP & Army Stationing and Installation Plan \\
\hline ATTACC & Army Training and Testing Area Carrying Capacity \\
\hline BLTM & Battalion Level Training Model \\
\hline C & Vegetative Cover Factor \\
\hline CATS & Combined Arms Training Strategy \\
\hline СMTC & Combat Maneuver Training Center \\
\hline DEMs & Digital Elevation Models \\
\hline DOD & Department of Defense \\
\hline ES & Erosion Status \\
\hline ESF & Event Severity Factor \\
\hline FTX & Field Training Exercise \\
\hline GIS & Geographic Information System \\
\hline ITAM & Integrated Training Area Management \\
\hline $\mathrm{K}$ & Soil Eerodibility Factor \\
\hline LCTA & Land Condition Trend Analysis \\
\hline LS & Slope Length and Steepness Factor (topography) \\
\hline MIM & Maneuver Impact Miles \\
\hline NRCS & Natural Resources Conservation Service \\
\hline ODCSOPS & Office of the Deputy Chief of Staff for Operations and Plans \\
\hline$P$ & Conservation Practices Factor (effectiveness) \\
\hline
\end{tabular}




$\begin{array}{ll}\text { R } & \text { Rainfall and Runoff Factor (climate) } \\ \text { RFMSS } & \text { Range Facility Management Support System } \\ \text { RUSLE } & \text { Revised Universal Soil Loss Equation } \\ \text { S } & \text { Linear Sensitivity Coefficient } \\ \text { T } & \text { Soil Loss Tolerance Factor } \\ \text { TIF } & \text { Training Impact Factors } \\ \text { USDA } & \text { U.S. Department of Agriculture } \\ \text { VCF } & \text { Vehicle Conversion Factor } \\ \text { VOF } & \text { Vehicle Off-road Factor } \\ \text { VSF } & \text { Vehicle Severity Factor }\end{array}$




\section{References}

Anderson, A.B., L. Chenkin, L. Winters, R. Hunt, C. Couvillon, D. McFerren, S. Sekscienski, P. Sydelko. 1996. "Evaluation of Land Value Study (ELVS)/ Army Training and Testing Area Carrying Capacity (ATTACC).” Pp. 8-17 in 5th Annual LRAM/ITAM Workshop Proceedings. August 27-29, 1996. LaCrosse, Wisconsin.

Anderson, A.B., W.L. Sprouse, D.G. Kowalski, and P.J. Guertin. 1995. LCTA Users Interface Program, Users Manual Version 1.0. USACERL ADP Report 95/24/ADA 300797. August 1995.

Box, G.E.P., M.G. Hunter, and J.S. Hunter. 1978. Statistics for experimenters: an introduction to design, data analysis, and model building. New York: John Wiley and Sons.

Concepts Analysis Agency. 1996a. Evaluation of Land Value Study (ELVS). US Army Concepts Analysis Agency, Study Report CAA-SR-96-5, Bethesda, Maryland.

Concepts Analysis Agency. 1996b. Evaluation of Land Value Study II (ELVSII). US Army Concepts Analysis Agency, Study Report CAA-SR-96-53, Bethesda, Maryland.

Council on Environmental Quality. 1989. Defense Lands and Installations. Environmental Quality: Annual Report, 1987-88. Washington, DC.

Gnanadesikan, R. 1977. Methods for statistical data analysis of multivariate observations. New York: John Wiley and Sons.

Guertin, P.J., J.F. Paruzinski, C. Rewerts, and A.B. Anderson. 1997. "Maneuver Impacts Distribution Modeling." 1997 ITAM 6th Annual Workshop. 26-28 August, 1997, San Antonio, TX.

Linn, J., and C.C. Gordon. 1993. "Mapping Training Area Disturbance on the Fort Carson Military ReseRation." Geographic Information Systems: Proceedings of the Seventh Annual GRASS Users Conference, March 16-19, 1992, Lakewood, Colorado. U.S. Department of Interior, Technical Report NPS/NRGISD/NRTR-93/13.

Renard, K.G., C.R. Foster, G.A. Weesies, D.K. McCool, and D.C. Yoder. 1997. Predicting Soil Erosion by Water: A Guide to Conservation Planning With the Revised Universal Soil Loss Equation (RUSLE). U.S. Department of Agriculture, Agriculture Handbook Number 703. Government Printing Office, Washington, DC.

Rogler, V.H., and U. Schwertmann. 1981. Erosivitat der Niederschlage und Iso-erodentkarte Bayerns. Zeitschrift Fur Kulturtechnik un Flurbereinigung, 22:99-112.

Sedlak, M.A., and S. Brown. 1992. "Maneuver Activity Damage Assessment Model Applications to Predicting the Effects of the Restationing of the 5th Infantry Division (Mech) to Fort Hood, Texas." Report to Fort Hood, TX. Texas A\&M Research Foundation, College Station, TX. 
U.S. Army Environmental Center (AEC). 1999. ATTACC Handbook (U.S. Army Environmental Center [AEC], Draft 1999).

Wischmeier, W.H., C.B. Johnson, and B.V. Cross. 1971. "A soil Erodibility nomograph for farmland and construction sites.” J. Soil and Water Conservation, 26:189-193.

Wischmeier, W.H., and D.D. Smith. 1978. Predicting rainfall erosion losses - a guide to conservation planning. U.S. Department of Agriculture, Agriculture Handbook 537. Government Printing Office, Washington, DC.

Wu, X., and J.D. Westervelt. 1994. Using Neural Networks to Correlate Satellite Imagery and Ground-truth Data. USACERL, Special Report EC-94/28/ADA 285486, August 1994, Champaign, IL. 


\section{USACERL DISTRIBUTION}

Chief of Engineers

ATTN: CEHEC-IM-LH (2)

ATTN: CEHEC-IM-LP (2)

ATTN: CECC-R

ATTN: CERD-L

ATTN:CERD-M

Army Headquarters

ATTN: DAMO-TRO

ATTN: SFIM-AEC-ECN

ATTN: ATIC-CTS

SERDP (2)

Defense Tech Info Center 22304

ATTN: DTIC-O (2) 